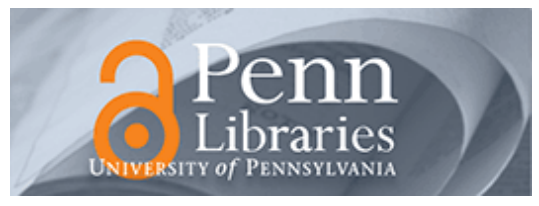

University of Pennsylvania

ScholarlyCommons

Marketing Papers

Wharton Faculty Research

7-2016

\title{
Complicating Decisions: The Work Ethic Heuristic and the Construction of Effortful Decisions
}

Rom Y. Schrift

University of Pennsylvania

Ran Kivetz

Oded Netzer

Follow this and additional works at: https://repository.upenn.edu/marketing_papers

Part of the Applied Behavior Analysis Commons, Behavioral Economics Commons, Cognition and Perception Commons, Cognitive Psychology Commons, Labor Economics Commons, and the Marketing Commons

\section{Recommended Citation}

Schrift, R. Y., Kivetz, R., \& Netzer, O. (2016). Complicating Decisions: The Work Ethic Heuristic and the Construction of Effortful Decisions. Journal of Experimental Psychology, 145 (7), 807-829.

http://dx.doi.org/10.1037/xge0000171

This paper is posted at ScholarlyCommons. https://repository.upenn.edu/marketing_papers/386

For more information, please contact repository@pobox.upenn.edu. 


\title{
Complicating Decisions: The Work Ethic Heuristic and the Construction of Effortful Decisions
}

\author{
Abstract \\ The notion that effort and hard work yield desired outcomes is ingrained in many cultures and affects our \\ thinking and behavior. However, could valuing effort complicate our lives? In the present article, the \\ authors demonstrate that individuals with a stronger tendency to link effort with positive outcomes end \\ up complicating what should be easy decisions. People distort their preferences and the information they \\ search and recall in a manner that intensifies the choice conflict and decisional effort they experience \\ before finalizing their choice. Six experiments identify the effort-outcome link as the underlying \\ mechanism for such conflict-increasing behavior. Individuals with a stronger tendency to link effort with \\ positive outcomes (e.g., individuals who subscribe to a Protestant Work Ethic) are shown to complicate \\ decisions by: (a) distorting evaluations of alternatives (Study 1); (b) distorting information recalled about \\ the alternatives (Studies 2a and 2b); and (3) distorting interpretations of information about the \\ alternatives (Study 3). Further, individuals conduct a superfluous search for information and spend more \\ time than needed on what should have been an easy decision (Studies $4 a$ and $4 b$ ).

\section{Disciplines} \\ Applied Behavior Analysis | Behavioral Economics | Business | Cognition and Perception | Cognitive \\ Psychology | Labor Economics | Marketing
}




\title{
COMPLICATING DECISIONS:
}

\section{THE WORK ETHIC HEURISTIC AND THE CONSTRUCTION OF EFFORTFUL DECISIONS}

\author{
Rom Y. Schrift, Ran Kivetz, and Oded Netzer*
}

March 2016

Forthcoming at the Journal of Experimental Psychology: General

* Rom Y. Schrift (roms@,wharton.upenn.edu) is an Assistant Professor of Marketing at the Wharton Business School, Ran Kivetz (rk566@gsb.columbia.edu) is the Philip H. Geier Professor of Business at Columbia University, and Oded Netzer (onetzer@gsb.columbia.edu) is an Associate Professor of Business, at Columbia University. The authors are grateful for the financial support of the Wharton Behavioral Lab and Wharton's Dean's Research Fund. 


\title{
COMPLICATING DECISIONS: THE WORK ETHIC HEURISTIC AND THE CONSTRUCTION OF EFFORTFUL DECISIONS
}

\begin{abstract}
The notion that effort and hard work yield desired outcomes is ingrained in many cultures and affects our thinking and behavior. However, could valuing effort complicate our lives? In the present article, the authors demonstrate that individuals with a stronger tendency to link effort with positive outcomes end up complicating what should be easy decisions. People distort their preferences and the information they search and recall in a manner that intensifies the choice conflict and decisional effort they experience prior to finalizing their choice. Six experiments identify the effort-outcome link as the underlying mechanism for such conflict-increasing behavior. Individuals with a stronger tendency to link effort with positive outcomes (e.g., individuals who subscribe to a Protestant Work Ethic) are shown to complicate decisions by: ( ) distorting evaluations of alternatives (Study 1); (ii) distorting information recalled about the alternatives (Studies $2 \mathrm{a} \& 2 \mathrm{~b}$ ); and (iii) distorting interpretations of information about the alternatives (Study 3). Further, individuals conduct a superfluous search for information and spend more time than needed on what should have been an easy decision (Studies $4 a \& 4 b)$.
\end{abstract}




\section{Introduction}

"According to the effort is the reward."

$\sim$ Rabbi Ben Hei (Babylonian Talmud, Pirkei Avot, 2nd century)

"There is no success without effort."

$\sim$ Sophocles

The ethos that effort and hard work yield desired outcomes is ingrained in our lives and cultures. Whether through bedtime stories at a young age (e.g., Three Little Pigs and The Little Red Hen) or popular slogans such as "no pain, no gain," the perceived link between effort and positive outcomes often influences our thinking and behavior. As Theodore Roosevelt stated: "It is only through labor and painful effort...that we move on to better things." Such work ethic may be functional and serve an important and fundamental purpose, such as fostering the sense that one can impact the world in a predictable way (e.g., the just-world hypothesis; Lerner, 1980). However, can a work ethic heuristic impede decision-making when important decisions seem too easy? In particular, would such a heuristic lead people to unconsciously construct a more effortful choice process, and behave in a manner that effectively complicates what should have been an easy decision?

The extant literature highlights situations in which people limit their deliberations and simplify their decisions in order to make easy, confident, and justifiable choices (see Brownstein 2003 for a comprehensive review). For example, researchers have shown that people often engage in selective information processing that favors one alternative over others (e.g., Janis \& Mann, 1977; Svenson, 1992). Such biased processing of alternatives, which decreases choice conflict and facilitates easier, more confident decisions, is consistent with several prominent theories, such as choice certainty theory (Mills, 1968), conflict theory (Janis \& Mann, 1977; Mann, Janis, \& Chaplin, 1969), 
differentiation and consolidation theory (Svenson, 1992), and search for dominance structure (Montgomery, 1983). Research on motivated reasoning (e.g., Kunda, 1990), motivated judgment (e.g., Kruglanski, 1990), motivated inference (e.g., Psyzczynski \& Greenberg, 1987), confirmation bias (e.g., Lord, Ross, \& Lepper, 1979), distortion of information (e.g., Russo, Medvec, \& Meloy, 1996), and choice under incomplete information (e.g., Kivetz \& Simonson, 2000) leads to related predictions of simplifying decisions and bolstering preferred alternatives. The upper pane of Figure 1 schematically portrays pre-decisional simplifying and bolstering patterns in the utility (option attractiveness) space. It is important to note that the aforementioned pre-decisional bolstering patterns are directionally consistent with those hypothesized and explained by dissonance reduction (Festinger, 1957) and/or self-perception (Bem, 1967). However, dissonance and self-perception refer to post-decisional phenomena rather than predecisional simplifying patterns.

Although research on simplifying decision processes is ubiquitous, some research has also analyzed conditions under which such simplifying behavior is attenuated. More specifically, as part of the tradeoff that individuals make between effort and accuracy, a motivation to make accurate decisions can decrease the use of decision heuristics and attenuate simplifying processes (e.g., Chaiken, 1980; Payne, Bettman, \& Johnson, 1988). Relatedly, research on cognitive closure (e.g., Kruglanski \& Webster, 1996; Mayseless \& Kruglanski, 1987) also explored conditions under which individuals seek to avoid closure, such as when cost of closure is high, judgmental mistakes are costlier, and when validity concerns are salient. In such instances, researchers found opposite decision patterns compared to those observed under a heightened need for closure. Specifically, individuals seeking to avoid cognitive closure were found to engage in a more thorough and extensive information processing and generate multiple alternative interpretations for what they observed (see Kruglanski \& Webster, 1996 for a review). Directly examining pre- 
decisional bolstering, Russo, Meloy, \& Wilks (2000) found that informing decision-makers that they will have to justify their decisions to others attenuated pre-decisional bolstering.

While the extant literature focused on understanding when and why decisionmakers simplify their choices, the present research demonstrates that people sometimes complicate their choices by making decisions more effortful than they ought to be. It is important to note that throughout the paper we use the term "complicating" to describe a set of behaviors that ultimately increase the effort that decision makers exert while making their decisions. However, we do not suggest that decision makers are aware that they are complicating their decisions or that decision makers want to complicate their decisions. Unlike simplifying processes, which are characterized by the spreading of evaluations, complicating patterns can be characterized by the convergence of evaluations. Such convergence in the evaluation of alternatives makes choosing harder. The lower pane of Figure 1 illustrates pre-decisional convergence of evaluations in the utility space. It is important to note that we conceptualize such effort enhancing behavior not as merely the attenuation of simplifying (or heuristic based) processing due to heightened motivation for accuracy, but rather as a bias in the exact opposite direction. In particular, in most of our studies we test for complicating behavior not only by vetting it against conditions that trigger simplifying patterns, but also against contextindependent control conditions in which no biased processing occurs. 
Figure 1. Simplifying versus Complicating Patterns in the Pre-decisional Phase

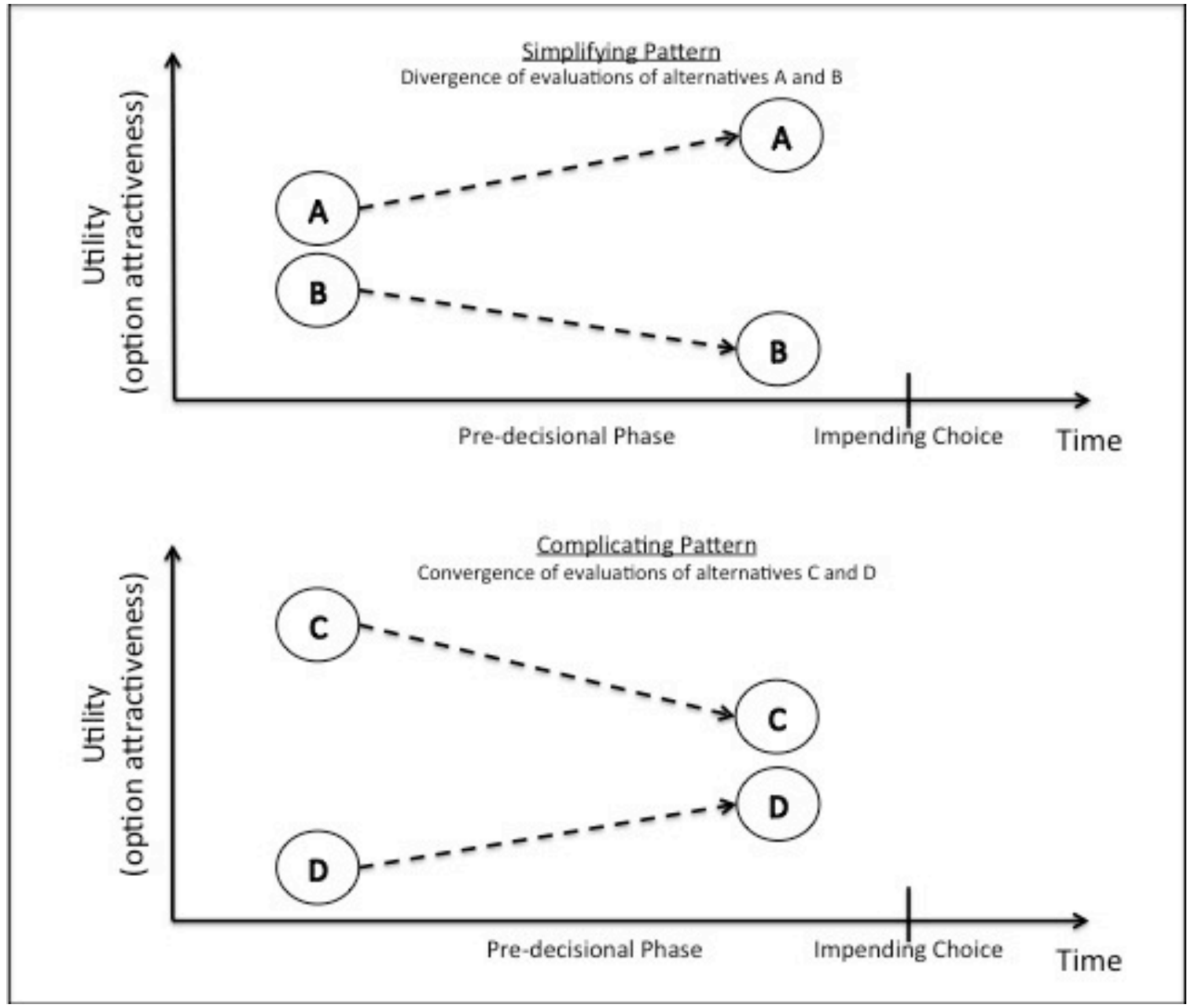

The Effort-Outcome Link

To understand what could lead people to engage in behaviors that effectively complicate their decision-making, it is useful to consider past research on perceptions of an effort-outcome link. Effort has been shown to trigger several inferential and motivational processes that affect our judgment and decision-making. For example, research has demonstrated that decision-makers perceive products and objects to be of higher quality when greater effort was expended in producing them (Kruger et al., 2004). Relatedly, 
consumers reward firms (through higher willingness to pay and increased preference) that exert extra effort to make or display products (Morales, 2005). Additionally, Kivetz and Zheng (2006) showed that people use their invested effort as a justification for selfgratification and indulgence, a finding consistent with the Protestant ethic of "earning the right to indulge" (Kivetz \& Simonson, 2002; Weber, 1958).

Related to the proposed effort-outcome link, recent research has documented instances in which decision-makers value effort during goal pursuit (Labroo and Kim, 2009; Kim and Labroo, 2011). In particular, Labroo and Kim (2009) showed that an object, which serves as a means to a certain goal, is perceived as more instrumental in achieving the goal when it is associated with effort and difficulty. For example, participants primed with a hedonic goal preferred a chocolate that was described with an ad that was more difficult, rather than easy, to visually process. Thus, the naïve belief that effort signals instrumentality made individuals value harder-to-process stimuli more, when such stimuli served as means to a goal.

Consistent with these findings, we argue that the general belief that effort is linked with positive outcomes impacts decision-making. More specifically, we argue that the level of difficulty that people experience when making decisions affects whether they construe their decision process as sufficiently diligent, and accordingly, whether people end up simplifying or complicating their decisions. We hypothesize that, because people tend to believe that positive outcomes are usually the "fruit" of effortful decision-making, lack of effort can give rise to processes in which people end up constructing a more effortful (or diligent) choice process. In essence, we propose that decision-makers unconsciously use the degree of effort in choice as a cue for assessing the decision quality. As is the case with many other heuristics, although using such an effort-outcome or (work ethic) heuristic may often be reasonable and helpful, over-applying it may lead to biases and counter-productive decision-making (e.g., Kahneman, Slovic, \& Tversky, 1982). 
Such a fallacy in conditional reasoning, termed "denying the antecedents" (Thompson, 1994) is well documented. Considerable research has demonstrated that the conditional "if $a$ then $b$ " often invites the inference "if not $a$ then not $b$ " (e.g., Braine, Reiser, \& Rumain, 1984; Evans, 1982; Taplin \& Stuadenmayer, 1973). Consistent with these findings we argue that the belief that effort $(e)$ yields positive outcomes $(p)$ invites the inference that a lack of effort (not $e$ ) is likely to lead to a lack of positive outcomes (not $p)$. Accordingly, when confronted with seemingly easy decisions, individuals may unconsciously associate such effortless decisions with negative (or non-positive) outcomes and therefore end up expending greater effort in their choice without realizing that such superfluous effort is neither warranted nor helpful in attaining better outcomes.

The aforementioned reversal in conditional probability is also consistent with research about causal versus diagnostic contingencies. In particular, Quattrone \& Tversky (1984) found that people select actions that are diagnostic of favorable outcomes even though the actions do not cause those outcomes. Importantly, similar to Quattrone \& Tversky (1984), we argue that people are not aware of their tendency to make decisions in a manner that is diagnostic, although not causally determinative, of favorable outcomes. Accordingly, we predict that, even in cases in which effort is not a causal determinant of a positive outcome, a work ethic heuristic will lead individuals to engage in decision processes that yield more effortful choices.

We posit that people may engage in a number of different behaviors that effectively complicate their decisions. For example, decision makers may distort their preferences and perception of alternatives in a manner that intensifies choice conflict. Additionally, decision makers may expend greater effort when making a decision by conducting a superfluous search for information and spending greater time on the decision.

The notion that decision-makers complicate their choices under certain conditions is consistent with recent research findings (Schrift, Netzer, \& Kivetz, 2011; Sela \& 
Berger, 2012). In particular, Schrift et al. (2011) demonstrate that decision-makers seek to attain compatibility between the effort they anticipate in a certain decision context and the effort they actually exert. Incongruity between the anticipated and experienced effort triggers simplifying or complicating decision processes, based on the direction of the gap. Accordingly, Schrift et al. (2011) found that when decision-makers encountered a harderthan-expected choice, they reduced choice conflict by bolstering their preferred (and ultimately chosen) alternative, a finding consistent with the extant literature on simplifying processes. In contrast, when decision-makers faced an easier-than-expected (yet important) choice, they intensified their choice conflict by bolstering an unattractive (near-dominated) alternative. Importantly, after such decision-makers complicated their choice -- in a manner that increased their decision effort and due diligence -- they still chose their preferred (and near-dominant) alternative, thus exhibiting what might be termed the "illusion of choice."

In the present research, we both extend the aforementioned findings to domains beyond choice (i.e., memory and pre-decisional processing of information) and investigate the psychological mechanism underlying complicating behavior. We propose that people's belief about an effort-outcome link drives processes that effectively complicate decision-making. In particular, we hypothesize that individuals who perceive a strong link between the effort invested in a decision and the quality of that decision will be more likely to end up complicating what may appear to be an easy (or even "nonexistent") decision. In contrast, individuals who do not believe in a strong effortoutcome link are less likely to exhibit patterns that complicate their decision process.

It is important to emphasize that we do not argue that individuals consciously complicate their decisions; rather, we posit that people follow a work-ethic heuristic that is over-generalized (over-applied) and that could lead to unintended complicating patterns. Further, we acknowledge that such non-conscious processes may be driven by different forms of automaticity, such as an habitual response learned over time (e.g., Dickinson, 
1985; Wood \& Neal, 2007) or an automatic goal pursuit (e.g., Bargh, 1997; Bargh et al. 2001). Disentangling the habit-formation and automatic goal pursuit explanations, to the extent these two constructs can be clearly differentiated at all (e.g., Aarts and Dijksterhuis 2000), is beyond the scope of the current paper. Nevertheless, in the General Discussion, we discuss how the findings relate to different forms of automaticity.

In order to test our conceptualization and the related hypotheses, we manipulate people's perception of the effort-outcome link (Studies $1 \& 3$ ) and demonstrate the role of such perceptions in moderating complicating behavior. In addition, we test the aforementioned hypotheses by measuring decision-makers' chronic tendency to link effort with positive outcomes (Studies 2a, 4a \& 4b). Specifically, we use the Protestant Work Ethic (PWE) scale (Mirels \& Garrett, 1971) and find that individuals with stronger PWE beliefs are more likely to engage in behaviors that complicate decisions. Overall, in a series of six studies, we find that individuals with a stronger belief in the effort-outcome link (hereafter, "EOL") are more likely to complicate easy decisions and intensify choice conflict by distorting their preferences (Study 1), distorting recalled information about choice alternatives (Studies $2 \mathrm{a} \& 2 \mathrm{~b}$ ), and distorting incoming information (Study 3); we also find that people with a stronger belief in the effort-outcome link end up exerting more effort in the choice by seeking more information and spending more time before finalizing their decisions (Studies $4 \mathrm{a} \& 4 \mathrm{~b}$ ).

It is important to note that, according to our conceptual framework, the belief in the effort-outcome link is expected to moderate complicating behavior but not simplifying behavior. That is, when a decision feels too easy, beliefs about the effortoutcome link (i.e., a work ethic heuristic) will cause individuals to expend greater effort on making their choice. However, when the decision is already difficult, simplifying behavior is triggered by other mechanisms, such as the need to justify choices and/or increase choice certainty and confidence. 


\section{Study 1: Simplifying, Complicating, and the Effort-Outcome Link}

Study 1 explores the entire continuum of pre-decisional distortions as a function of choice difficulty. In particular, we test for divergence of evaluations (i.e., simplifying) and convergence of evaluations (i.e., complicating) before choices are made by participants facing difficult, moderately difficult, and easy decisions. In addition, we explore the moderating effect that EOL beliefs have on complicating behavior. We predict that individuals with strong beliefs in the EOL will converge their evaluations in the pre-decisional stage (i.e., complicate their decisions) when confronted with an easy decision. In contrast, individuals who perceive the EOL as weak will not converge their evaluations in a manner that complicates their decisions.

\section{Method}

Participants and Procedure. Two hundred and fourteen (214) paid undergraduate students from a large East Coast university participated in this study. ${ }^{1}$ In the first part of the study, participants reviewed 10 different fictitious company logos and were asked to rank and then rate each logo on a 0-15 liking scale. In the second part of the study, after completing an unrelated filler task, we manipulated participants' perceptions of the EOL to be either strong or weak using a well-established paradigm of manipulating metacognitive experiences (see, e.g., Schwarz et al., 1991). We discuss the specifics of the EOL manipulation and its procedure in the next section. In the third and last part of the study, participants were asked to imagine that they had recently created their own new company, and they then read an excerpt emphasizing the importance of choosing an attractive company logo. Then, participants were asked to choose between two logos selected randomly from the ten logos they had originally rated. Prior to choosing

\footnotetext{
${ }^{1}$ Eight participants did not complete the study due to technical failures in the computer-based survey and three participants did not comply with the survey's instructions and were therefore omitted from the analysis.
} 
between the two logos shown to them, participants re-rated these two logos on the same 0-15 liking scale used in the first part of the study. Thus, the rate-rerate procedure enabled us to examine if, and in what direction, participants changed their evaluations of the logo stimuli (prior to making a choice). The ratings in the first part of the study represent a "context-independent" measure of overall liking at the individual level. In contrast, the ratings in the last part of the study reflect participants' preferences within the context of the impending choice (pre-decisional phase). In order to account for statistical artifacts (e.g., regression to the mean) that could potentially arise from the test-retest design, we also employed a control condition in which participants rated all 10 logos and then re-rated the logos outside the context of any choice.

It is important to note that because the two logos that formed the choice set were drawn randomly from the original 10 , we were able to explore pre-decisional preference distortions at varying degrees of difficulty. In particular, the random procedure ensured that some participants received a difficult logo choice, whereas others received a moderately difficult choice, and yet others received an easy choice, based on their own previously stated preferences. More specifically, the closer the original evaluations of the two randomly drawn logos were, the more difficult the choice should be for the participant. Conversely, the farther apart the two logos were originally rated, the easier is the choice (as one logo is clearly preferred to the other). Based on our conceptualization, we expected to observe complicating of easy decisions among participants that perceive the effort-outcome link as strong, but not among participants who perceive the EOL as weak.

Effort-Outcome Link Manipulation. As noted earlier, after participants completed the first part of the study (the first "context-independent" logo rating procedure), we varied their perceptions of the EOL using a well-established paradigm of manipulating metacognitive experiences (Schwarz et al., 1991). In particular, participants read a short statement that supported the effort-outcome link: "A person who is willing and able to work hard and invest a lot of effort will generate positive outcomes and success in life." After 
reading this statement, participants were asked to think about their personal experiences in life and write down one (1) versus five (5) experiences (manipulated between-subjects) that are consistent with the statement they had just read. Because people generally tend to agree more with statements for which they can easily retrieve examples, asking participants to retrieve only one example (an easier task) should make them agree with the statement more, compared to those asked to retrieve five examples (a harder task). Thus, consistent with well-established findings concerning ease-of-retrieval (e.g., Schwarz et al., 1991), participants assigned to the one-example condition should perceive the EOL to be stronger than those assigned to the five-examples condition.

Admittedly, one could argue that merely asking participants to come up with five examples (as opposed to one) may impact simplifying and/or complicating behavior in the subsequent choice task due to other reasons, which are not related to EOL perceptions. For example, the increased difficulty in coming up with five examples may deplete respondents and attenuate complicating behavior. In order to address this alternative explanation, we added two experimental conditions that employed an inverted manipulation of the EOL. More specifically, in these two additional conditions, participants read a statement which opposed (rather than supported) the effort-outcome link: "Sometimes in life, we encounter extremely good opportunities that generate positive outcomes even without working hard and investing too much effort." Participants assigned to these two conditions were asked to generate either one (1) or five (5) personal experiences (manipulated between-subjects) that are consistent with this statement. Therefore, unlike the supporting-statement conditions, in the opposing-statement conditions we expected that those participants who were asked to come up with five examples that oppose the EOL (a more difficult task) will perceive such a link to be stronger (and will demonstrate complicating behavior). The complete experimental design, which includes generating both examples supporting and refuting the EOL allows us to rule out alternative explanations pertaining to the number of examples 
participants generated. Figure 2 depicts the progression of Study 1 in each of the experimental conditions.

Figure 2. Progression of Study 1 in Each Condition

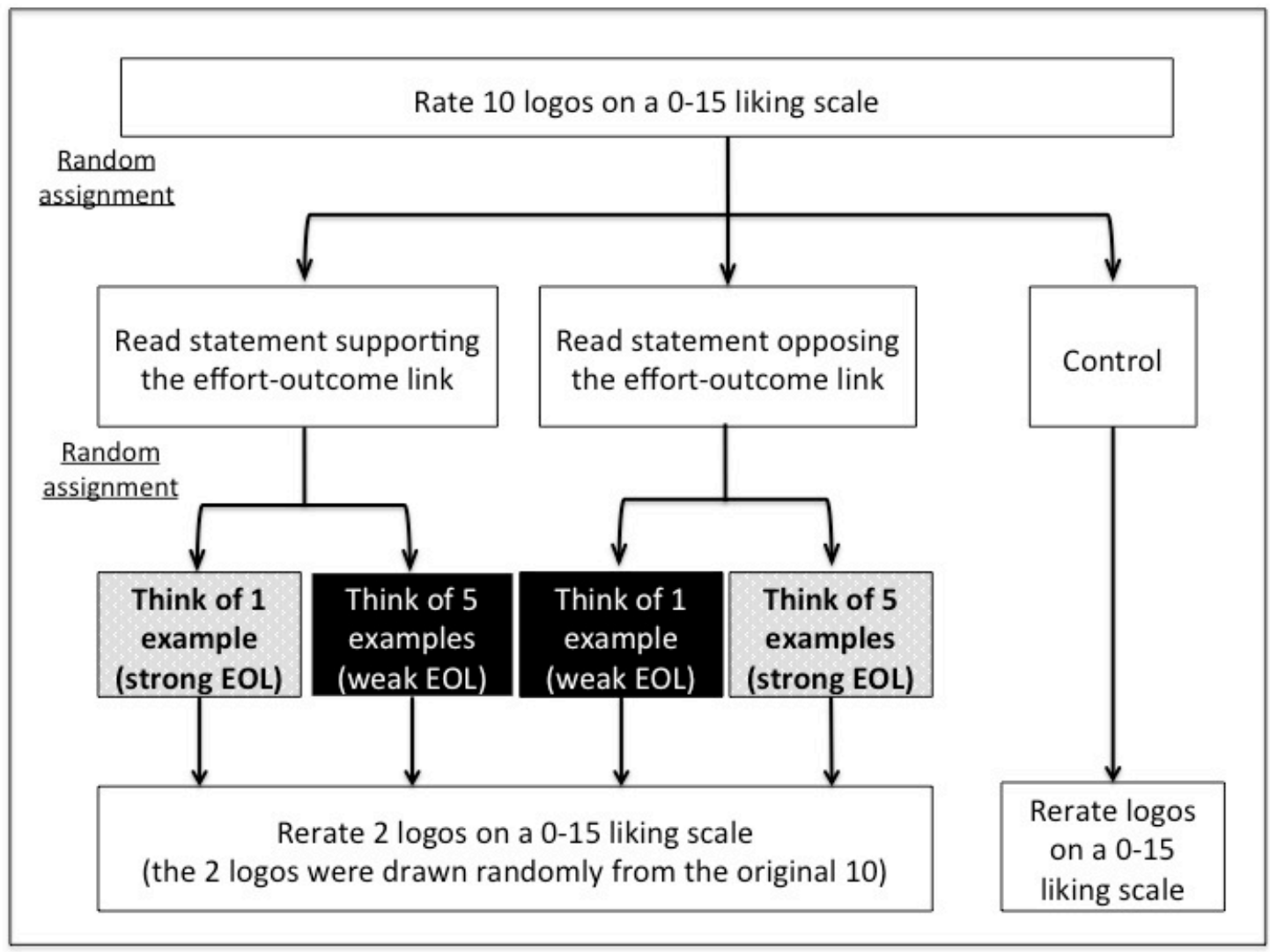

Two of the four conditions were intended to manipulate participants' perceptions of the EOL to be strong (i.e., the 1-example supporting-statement condition and the 5examples opposing-statement condition). As subsequently detailed, pre-test results indicate that there was no difference between these two conditions and they were collapsed to form a single "strong EOL" condition. Similarly, the two conditions that intended to manipulate the EOL to be weak (i.e., the 5-examples supporting-statement condition and the 1-example opposing-statement condition) were also statistically indistinguishable, thus these two conditions were collapsed to form a single "weak EOL" condition. 
Pretesting the EOL Manipulation. A pretest $(\mathrm{N}=109)$ verified that the EOL manipulation works as intended. Participants in the pretest viewed the same statements that either supported or opposed the EOL (manipulated between-subjects) and were asked to come up with either one or five personal experiences (manipulated between-subjects) that are consistent with these statements. After writing the examples participants were asked to indicate (on a 1-7 scale ranging from "strongly disagree" to "strongly agree") the extent to which they agreed that "only through hard work and investing effort one could attain positive outcomes and success in life." As expected, a 2 (statement: supporting vs. opposing the EOL) x 2 (personal experiences: 1 vs. 5) full factorial ANOVA revealed the expected crossover interaction $\left(\mathrm{F}(1,107)=8.96, p=.003, \eta_{\mathrm{p}}{ }^{2}=\right.$ .08). Specifically, participants assigned to the EOL-supporting-statement condition agreed more with the EOL statement when asked to come up with one as opposed to five examples that support the EOL $\left(\mathrm{M}_{1 \text {-supporting }}=4.46, \mathrm{SD}=1.68\right.$ vs. $\mathrm{M}_{5 \text {-supporting }}=3.44, \mathrm{SD}$ $=1.47, \mathrm{t}(53)=2.38, \mathrm{~d}=0.65, p<.03)$. An opposite pattern emerged for participants assigned to the EOL-opposing-statement conditions. In these conditions, participants agreed more with the EOL statement when asked to come up with five as opposed to one example that opposed the $\mathrm{EOL}\left(\mathrm{M}_{5 \text {-opposing }}=4.79, \mathrm{SD}=1.17\right.$ vs. $\mathrm{M}_{1 \text {-opposing }}=4.07, \mathrm{SD}=$ $1.65, \mathrm{t}(52)=1.84, \mathrm{~d}=.50, p=.07)$.

As previously mentioned, because the 1-example-supporting-statement condition and the 5-examples-opposing-statement conditions were statistically indistinguishable $(p>4)$ we collapsed these two conditions to form a single "strong EOL" condition. Similarly, the 5-examples-supporting-statement condition and the 1-example-opposingstatement condition $(p>.15)$ were collapsed to form a single "weak EOL" condition. Collapsing these conditions we find that participants in the strong-EOL condition were more likely to agree with the statement than were participants assigned to the weak-EOL condition $\left(\mathrm{M}_{\text {strong-EOL }}=4.63, \mathrm{M}_{\text {weak-EOL }}=3.75, \mathrm{~F}(1,107)=9.0, p=.003, \eta_{\mathrm{p}}{ }^{2}=.08\right)$. Further, the proportion of participants above the midpoint scale in the strong-EOL 
condition was significantly higher compared to the corresponding proportion in the weakEOL condition $\left(\mathrm{M}_{\text {strong-EOL }}=66.1 \%, \mathrm{M}_{\text {weak-EOL }}=41 \%, \chi^{2}(1)=6.16, p<.013, \varphi=.25\right)$.

\section{Main Study Results}

Decision Difficulty. Decision difficulty is an independent variable in this study. Specifically, we predicted that lower decision difficulty would give rise to complicating decision processes, whereas higher decision difficulty will lead to simplifying behavior. To test this prediction, we computed the choice difficulty for each participant based on that participant's original logo ratings. Specifically, we determined the level of decision difficulty using the absolute difference (i.e., dR1) in the overall-liking ratings (obtained in the first part of the study) of the two logos that were randomly selected to be later shown to that participant in the third stage of the study. A larger difference between the liking ratings of the two logos in the first stage (i.e., a larger $\mathrm{dR} 1$ ) means that the logo choice facing the participant is subjectively easier.

Dependent Variable. In order to examine whether, and to what extent, participants simplified versus complicated their decisions, we calculated the difference between the ratings of the two (randomly selected) logos in the first part of the study $(\mathrm{dR} 1)$ and in the second part (dR2). We defined a simplifying-complicating score (hereinafter, SC-score) as the change in the difference in ratings between the first and second parts of the study (i.e., $\mathrm{SC}=\mathrm{dR} 2-\mathrm{dR} 1)^{2}$. A positive $\mathrm{SC}$-score indicates that the overall liking scores of the two logos diverged (spread) prior to choice, that is, simplifying occurred. A positive SC-score demonstrates simplifying behavior because the logo that was preferred in the first rating occasion (relative to the other randomly

\footnotetext{
${ }^{2}$ Because the sign is important for our testing procedure, we examined whether any participant displayed reversal of ratings in the two measurements (i.e., instances in which a logo was rated as superior in the first measurement but inferior in the second measurement). Two instances of such rating reversals were observed, and dropping these observations or retaining them (by coding these responses counter to our prediction) did not significantly change the pattern of results.
} 
selected logo in the pair) became even more preferred in the second rating occasion, when participants were made aware that they would need to choose between the two selected logos. In contrast, a negative SC-score indicates that the overall liking scores of the two logos converged prior to choice, thereby signifying a complicating decision process. In particular, a negative SC-score means that the degree to which a logo was preferred in the first rating occasion (relative to the other randomly selected logo in the pair) became smaller in the second rating occasion, that is, once participants were notified that they would have to choose between the two selected logos.

Figures $3 \mathrm{a}$ and $3 \mathrm{~b}$ depict schematic examples of simplifying and complicating patterns (respectively) and their corresponding SC-scores. We used participants' SCscores to investigate both the direction and the magnitude of simplifying versus complicating behaviors. We also compared the SC-scores obtained in the experimental conditions with those obtained in the control condition to account for statistical artifacts (e.g., regression to the mean) that could potentially arise from the test-retest design. 
Figure 3a. A Schematic Example of a Calculated SC-Score for a Simplifying Pattern

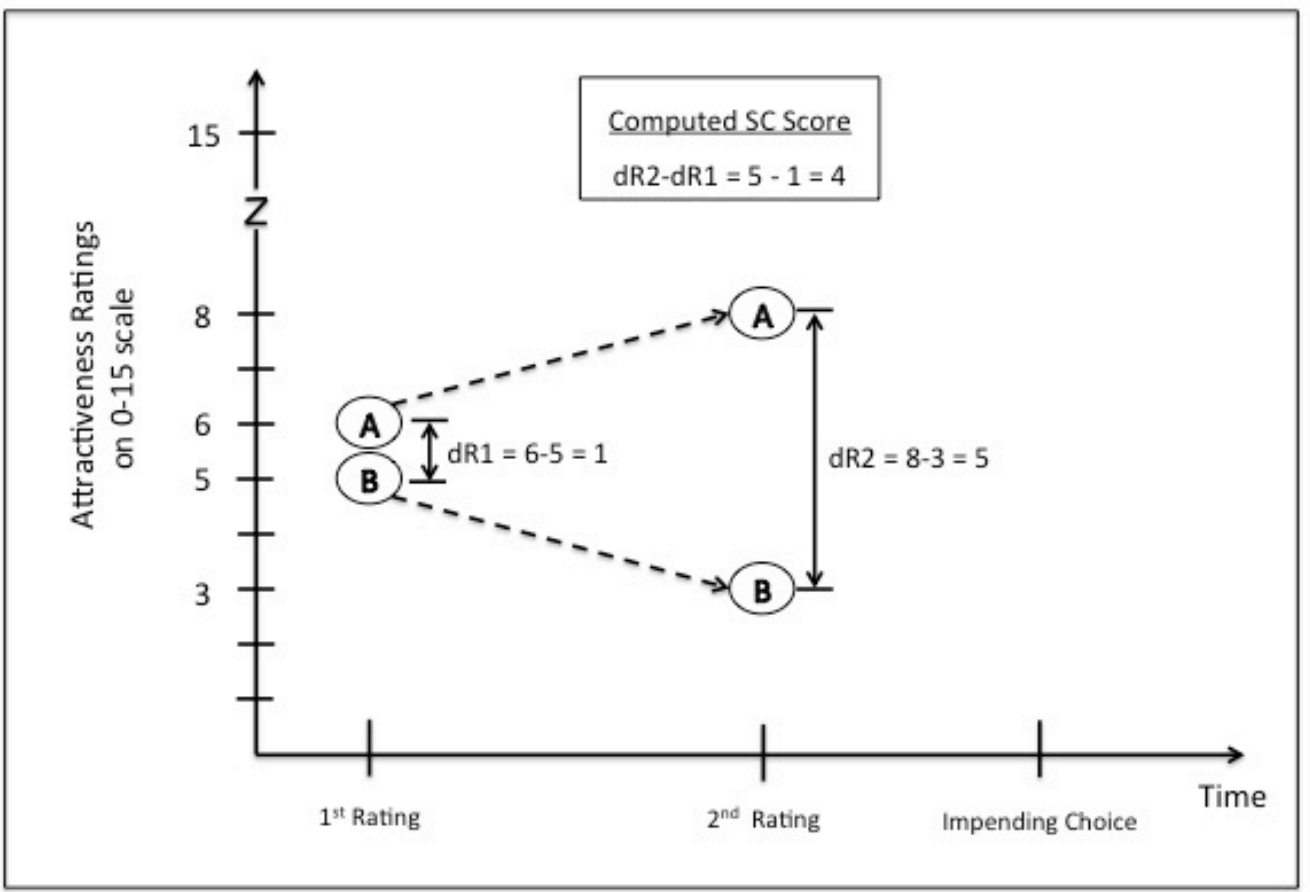

Figure 3b. A Schematic Example of a Calculated SC-Score for a Complicating Pattern

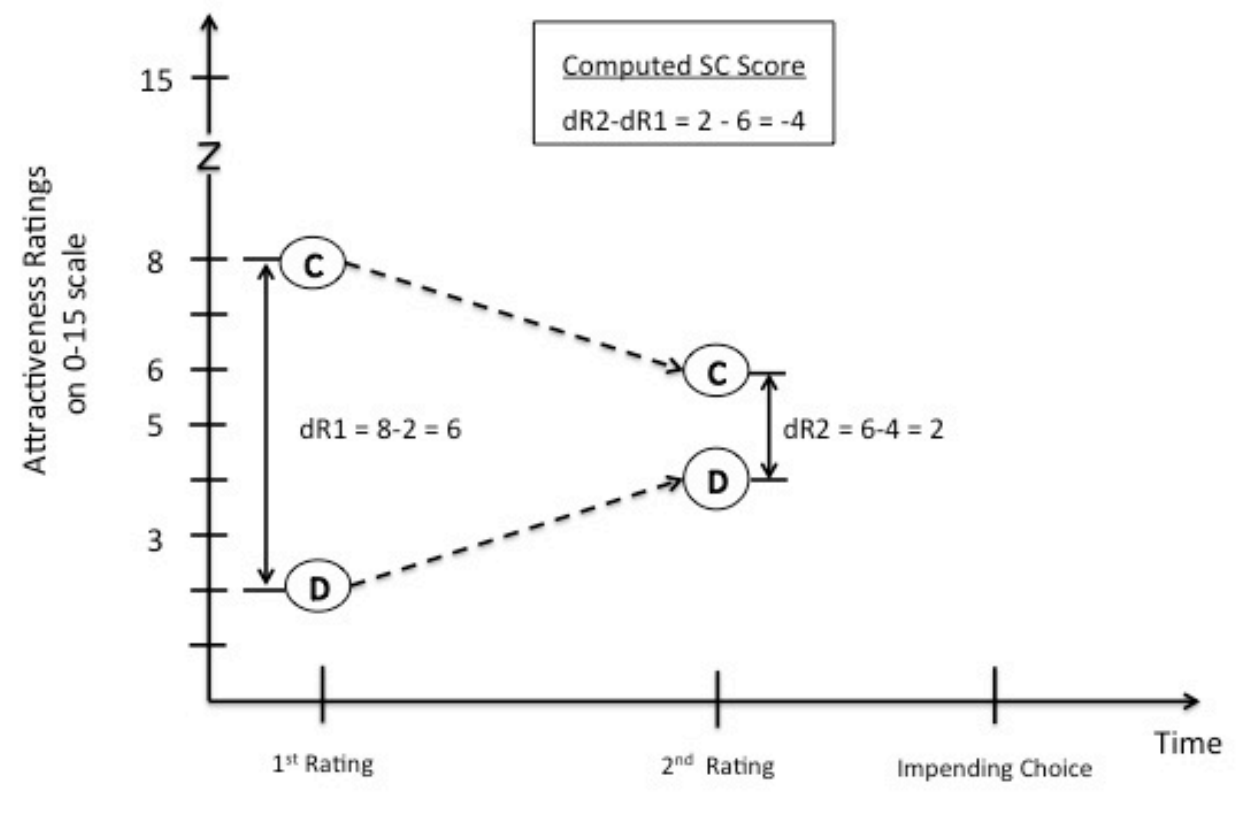


Analysis. We classified respondents into three levels of choice difficulty according to a tertiary split of their $\mathrm{dR} 1$ scores (the high-, moderate-, and low-decision difficulty groups had dR1 scores of 1.42 [SD $=1.01], 5.02$ [SD = 1.27], and 10.05 [SD = 1.64], respectively). Next, to test for simplifying versus complicating behavior, we computed the $\mathrm{SC}$-scores for each of these groups and in each condition. In order to account for statistical artifacts, all contrasts were performed relative to the control condition.

Low-Decision Difficulty. As hypothesized, participants assigned to the lowdecision difficulty condition complicated their decision in the strong-EOL condition $\left(\mathrm{SC}_{\text {strong-EOL }}=-2.63\right.$ vs. $\left.\mathrm{SC}_{\text {control }}=-.42, \mathrm{t}(46)=2.4, \mathrm{~d}=-0.72, p<.02\right)$ but not in the weakEOL condition $\left(\mathrm{SC}_{\text {weak-EOL }}=.85\right.$ vs. $\left.\mathrm{SC}_{\text {control }}=-.42, \mathrm{t}(52)=1.7, p>.09\right)$. That is, complicating patterns of low-difficulty decisions were apparent only for participants with strong beliefs in the EOL.

High- and Moderate-Decision Difficulty. Consistent with previous research, participants simplified their difficult choices in both the Strong- $\left(\mathrm{SC}_{\text {strong-EOL }}=2.39 \mathrm{vs}\right.$. $\left.\mathrm{SC}_{\text {control }}=.16, \mathrm{t}(47)=3.81, \mathrm{~d}=1.21, p<.001\right)$ and Weak-EOL conditions $\left(\mathrm{SC}_{\text {weak-EOL }}=\right.$ 2.16 vs. $\left.\mathrm{SC}_{\text {control }}=.16, \mathrm{t}(46)=3.09, \mathrm{~d}=0.99, p<.01\right)$. Further, such simplifying behavior attenuated at moderated levels of choice difficulty regardless of beliefs in the $\mathrm{EOL}\left(\mathrm{SC}_{\text {strong-EOL }}=0.67\right.$ vs. $\mathrm{SC}_{\text {control }}=-.04, p>.3$ and $\mathrm{SC}_{\text {weak-EOL }}=.11$ vs. $\mathrm{SC}_{\text {control }}=-.04$, $p>.8$ ). Table 1 summarizes the SC scores in the various conditions. As can be seen, in the strong EOL conditions the entire spectrum of behavior is observed; from the complicating of easy decisions to the simplifying of difficult decisions. 
Table 1. Simplifying-Complicating (SC) Scores in Study 1

\begin{tabular}{|l|ccc|}
\cline { 2 - 4 } \multicolumn{1}{c|}{} & \multicolumn{3}{|c|}{ Decision Difficulty } \\
\cline { 2 - 4 } & Low & Moderate & High \\
\hline Strong EOL & $\begin{array}{c}-2.63^{*} \\
\text { (complicating) }\end{array}$ & 0.67 & $\begin{array}{c}2.39^{*} \\
\text { (simplifying) }\end{array}$ \\
\hline Weak EOL & 0.85 & 0.11 & $\begin{array}{c}2.16^{*} \\
\text { (simplifying) }\end{array}$ \\
\hline
\end{tabular}

* Significantly different from the control

Continuous Analysis of Decision Difficulty. In order to address possible limitations of trichotomizing the data, we also employed a continuous analysis in which we regressed the SC score on: (i) level of decision difficulty (dR1); (ii) EOL manipulation; and (iii) the two-way interaction (regression $\mathrm{R}^{2}=.24$ ). As hypothesized, the level of decision difficulty $(\mathrm{dR} 1)$ had a significant impact on the SC score $\left(\mathrm{B}_{\text {decision }}\right.$ difficulty $=-.396, \mathrm{SE}=.07, p<.001)$ indicating that as $\mathrm{dR} 1$ increases (the easier the decision becomes) the greater is the convergence of evaluations (i.e., the more complicating behavior observed). No significant main effect was observed for the EOL manipulation $\left(\mathrm{B}_{\mathrm{EOL}}=.434, \mathrm{SE}=.44, p>.3\right)$. However, as expected, a significant interaction was observed $\left(\mathrm{B}_{\text {decision difficulty } x \mathrm{EOL}}=-.174, \mathrm{SE}=-.17, p=.013\right)$ indicating that the convergence of evaluations (complicating behavior) as decisions became easier was more pronounced among people who perceived the EOL as stronger.

In order to ensure that the type of manipulation of EOL (i.e., supporting versus opposing statements) did not produce a different pattern we have also ran a regression that included the manipulation type as an additional variable. No main effect or significant interactions were observed, thus further justifying our decision to collapse this 
variable. We refer the reader to Appendix A, which displays the pattern of results broken down by manipulation type.

\section{Discussion}

Study 1 explored the full continuum of possible preference distortions in the predecisional phase. In particular, while we replicated previous findings by demonstrating simplifying of difficult decisions, we also found that decision-makers engaged in behaviors that effectively complicated relatively easy decisions. Furthermore, we demonstrated the moderating role of effort-outcome perceptions in complicating processes through manipulating EOL. Respondents who perceived a strong EOL distorted their preferences prior to choice in a manner that intensified their choice conflict and made their decision seemingly harder. However, such behavior was not observed among respondents who did not perceive a strong relation between effort and positive outcomes.

In the next study, we further test the role of the EOL in driving complicating behavior by measuring decision-makers' chronic tendency to link effort with positive outcomes. We also explore an additional mechanism by which people may increase their choice conflict. Specifically, we show that decision-makers not only distort their preferences prior to making a choice (as in Study 1), but also distort their recall about alternatives in a manner that inflates choice conflict.

\section{Study 2a: Complicating Choice through Memory Distortion}

The purpose of this study is threefold. First, the present study further explores how perceptions of the EOL lead decision-makers to engage in behavior that complicates their decisions. In particular, in this study, we measured participants' chronic tendency to link effort with positive outcomes using the Protestant Work Ethic scale (Mirels \& 
Garrett, 1971). The scale measures the extent to which people endorse hard work and self-discipline using such items as: "Any man or woman who is able and willing to work hard has a good chance of succeeding," "Most people who don't succeed in life are just plain lazy," and "Hard work offers little guarantee of success" (reverse coded).

Second, this study investigates a different mechanism by which people may complicate their decisions. More specifically, we hypothesize that when asked to retrieve information from memory about the available alternatives, people who face a seemingly easy decision and who link effort with positive outcomes will distort their memories in a direction that intensifies the choice conflict. To test this hypothesis, we instructed the study participants to consider information about potential job candidates, and we subsequently asked the participants to recall this information prior to choosing which of two job candidates to hire. Unlike Study 1, which explored the entire spectrum of choice difficulty (from easy to difficult choices), the current study focuses only on relatively easy decisions that are hypothesized to give rise to complicating behavior. In particular, one of the two job candidates was described as more appealing, giving rise to what should have been an easy hiring choice.

Third, the current study examines rival accounts based on market-efficiency inferences and conversational norms (e.g., Prelec, Wernerfelt, \& Zettelmeyer, 1997; Grice, 1975; Schwarz, 1999). In particular, one could argue that respondents may question why the researcher had asked them to make an easy decision, and therefore conclude that the alternatives must be close in attractiveness. Additionally, study participants may infer that choice alternatives must lie on a pareto-optimal (efficient) frontier, because the competitive marketplace does not sustain dominated options (e.g., Chernev \& Carpenter, 2001). Such conversational norms and market-efficiency would tend to generate convergence in the evaluation of alternatives.

It is important to note that conversational norms (e.g., Grice, 1975; Schwarz, 1999) and market-efficiency (e.g., Chernev \& Carpenter, 2001) cannot account for the 
pattern of results observed in Study 1. Specifically, whereas such inferences should not interact with beliefs about the EOL, the findings from Study 1 show that complicating behavior was observed only among participants who perceived a strong EOL and was not observed among participants who perceived a weak EOL. Moreover, inferences related to market-efficiency are less likely to occur in domains with relatively large preference heterogeneity, as the location of the "efficient frontier" may vary across individuals. Because Study 1 employed stimuli (logos) whose evaluation is inherently subjective, inferences about market-efficiency and the "proper" spread between alternatives are less likely. Nevertheless, the present study was designed to directly test the market-efficiency inference and conversational norms rival accounts by manipulating two new variables: $(i)$ the timing of the potential memory distortion (i.e., pre- vs. post-decisional phase); and (ii) the decision's perceived importance. If inferences about market efficiency and conversational norms are driving the predicted distortions in memory, that is, respondents are questioning the researchers motives then such inferences and norms should be equally likely in the pre- and post-decisional phases. In contrast, according to our conceptualization, complicating behavior should only occur during the deliberation phase of an impending decision, that is, in the pre-decisional phase. Once the decision is finalized, distortions cannot impact the experienced conflict and perceived "due diligence" in making the choice (because the choice has already been made).

Additionally, and consistent with the effort compatibility hypothesis (Schrift et al. 2011), framing the decision as relatively unimportant should reduce one's motivation to conduct a diligent decision process. Accordingly, in this study, we also manipulate the decision's importance and expect to observe complicating patterns only when the decision is framed as important. However, we do not expect decision importance to interact with market efficiency or conversational norms. Thus, contrary to the marketefficiency inference and conversational norms accounts, we predict that complicating behavior will be: (i) observed only in the pre-decisional stages; (ii) present only when the 
decision is framed as important; and (iii) more pronounced among respondents who perceive a stronger EOL.

\section{Method}

Participants and Procedure. Two hundred and seventeen (217) undergraduate students from a large East Coast university participated in this two-part study. In the study's first part, participants were asked to imagine that they needed to make a hiring decision and were asked to review information about 12 job candidates before deciding whom to hire for a senior position in their company. Each potential candidate was described on four dimensions: name, GMAT score, recommendation-based evaluation (with a score ranging from 0 to 3), and interview-based evaluation (with a score ranging from 0 to 3). After reviewing the information about all of the job candidates, participants completed an unrelated filler task and then advanced to the second part of the study. In this second part, participants were asked to make a choice between two of the candidates they had previously reviewed. One of the two candidates had a better GMAT score (706 vs. 678 ) and a better recommendation-based evaluation (2.9 vs. 1.8). However, the information describing the interview-based evaluation was withheld (i.e., was missing) for both job candidates (the original values that participants observed in the first part of the study were identical for both job candidates: 1.1 out of 3 ). Thus, based solely on the available information, the choice seemed relatively easy, as one candidate dominated the second on both available attributes (GMAT score and recommendation-based evaluation). After participants completed the two parts of the study, they were asked to complete multiple items taken from the Protestant Work Ethic scale (Mirels \& Garrett, 1971). ${ }^{3}$

The study's first factor (manipulated between-subjects) was the timing of the recall relative to the choice. More specifically, participants were randomly assigned to one of

\footnotetext{
${ }^{3}$ Seven participants were dropped from the analyses because their PWE scale measures were missing from the data.
} 
two conditions: (1) a condition in which they were asked to complete the missing information from memory before choosing which job candidate to hire (pre-decisional condition); and (2) a condition in which they were asked to complete the missing information from memory immediately after choosing which job candidate to hire (postdecisional condition).

The second factor was the decision's importance (high vs. low, manipulated between subjects; based on Jecker 1964). In the low-importance condition, participants were told that although they will need to choose which of the two candidates to hire, since the company is rapidly expanding there is a very good chance that eventually both candidates will be hired. In the high-importance condition, participants were told that only one of the two candidates could be hired.

In order to measure the baseline recall of information outside the context of choice, we also employed a control condition to which some respondents were randomly assigned. In this control condition, participants were asked to complete the missing information from memory but neither made, nor expected to make, any choice between the job candidates.

\section{Results}

Dependent Variable. In order to examine whether, and to what extent, participants simplified versus complicated their decisions, we calculated the difference between the recalled interview-based evaluation scores for the two job candidates, and then formed an SC-Score. We subtracted the interview-based evaluation score recalled for the inferior candidate from the corresponding score recalled for the superior candidate. Because the original (true) interview-based evaluation scores of the two candidates were identical (i.e., 1.1 out of 3), a difference of zero indicates that the relative attractiveness of the candidates was not distorted (or at least, not misremembered) by participants. A positive difference indicates that participants recalled the information in a 
manner that bolstered the relative attractiveness of the better candidate, that is, a simplifying pattern. Conversely, a negative difference signifies complicating behavior, because the (distorted or inaccurate) memory boosts the relative attractiveness of the inferior candidate.

Manipulation Check. A post-test $(\mathrm{N}=82)$ verified that the decision importance manipulation worked as intended. Participants that received the same aforementioned scenario and were randomly assigned to one of the two decision-importance conditions reported: ( $i$ ) being more motivated to choose the best candidate in the high (vs. low) importance condition $\left(\mathrm{M}_{\text {high importance }}=6.51\right.$ vs. $\mathrm{M}_{\text {low importance }}=5.3, \mathrm{~F}(1,80)=30.49, p<$ $.001, \eta_{\mathrm{p}}{ }^{2}=.23$; on scale of 1-7 ranging from not at all motivated to extremely motivated); and (ii) perceiving the decision as more important in the high (vs. low) importance condition $\left(\mathrm{M}_{\text {high importance }}=6.42\right.$ vs. $\mathrm{M}_{\text {low importance }}=4.9, \mathrm{~F}(1,80)=47.1, p<.001, \eta_{\mathrm{p}}{ }^{2}=.37$; on scale of 1-7 ranging from not at all important to extremely important).

Analysis. We regressed the dependent variable (SC-Score) on all three factors: (1) timing-of-recall; (2) decision importance; and (3) the participant's score on the Protestant Work Ethic scale (mean centered). We also included in the regression model all two-way interactions and the single three-way interaction (regression $\mathrm{R}^{2}=.13$ ). As expected, a significant two-way interaction between timing-of-recall and decision importance was observed $\left(\mathrm{B}_{\text {timing of recall } \mathrm{x} \text { importance }}=-.17, \mathrm{SE}=.05, p<.01\right)$, indicating that pre-decisional complicating behavior was more pronounced when the decision was framed as more important (Figure 4). In particular, in the high importance conditions, the SC-Score was negative and significantly different from the control only in the predecisional condition $\left(\mathrm{M}_{\text {pre }}=-0.45, \mathrm{SD}=.67, \mathrm{M}_{\text {control }}=-0.01, \mathrm{SD}=.66, \mathrm{t}(85)=3.1, \mathrm{~d}=-\right.$ $.66, p=.003)$ but not in the post-decisional condition $\left(\mathrm{M}_{\mathrm{post}}=-0.06, \mathrm{SD}=.79, \mathrm{t}(86)=.3\right.$, $p>.7)$. As expected, in the low importance conditions, the SC-Scores were not significantly different from the control in either the pre- or post-decision phase $\left(\mathrm{M}_{\text {pre }}=0.04, \mathrm{M}_{\text {post }}=-0.21, \mathrm{M}_{\text {control }}=-0.01\right.$, both $p$ 's $\left.>.16\right)$. 
Additionally, a significant two-way interaction between timing-of-recall and the Protestant Work Ethic scale was observed $\left(\mathrm{B}_{\text {timing of recall } \mathrm{x} \text { PWE }}=-.012, \mathrm{SE}=.005, p<.02\right)$, indicating that participants with stronger Protestant Work Ethic beliefs exhibited greater complicating behavior in the pre-decisional stage compared to participants with weaker Protestant Work Ethic beliefs.

Finally, and consistent with our predictions, the three-way interaction was statistically significant $\left(\mathrm{B}_{\text {timing of recall } \mathrm{x} \text { importance } \mathrm{xPE}}=-.011, \mathrm{SE}=.005, p<.02\right)$, indicating that participants with stronger PWE beliefs exhibited greater complicating behavior in the pre-decisional phase of important decisions (compared to participants with lower PWE scores). No other main effects or interactions approached statistical significance.

Figure 4. Memory Distortions (Simplifying-Complicating Scores) in the Pre- and PostDecisional Stages as a Function of Decision Importance

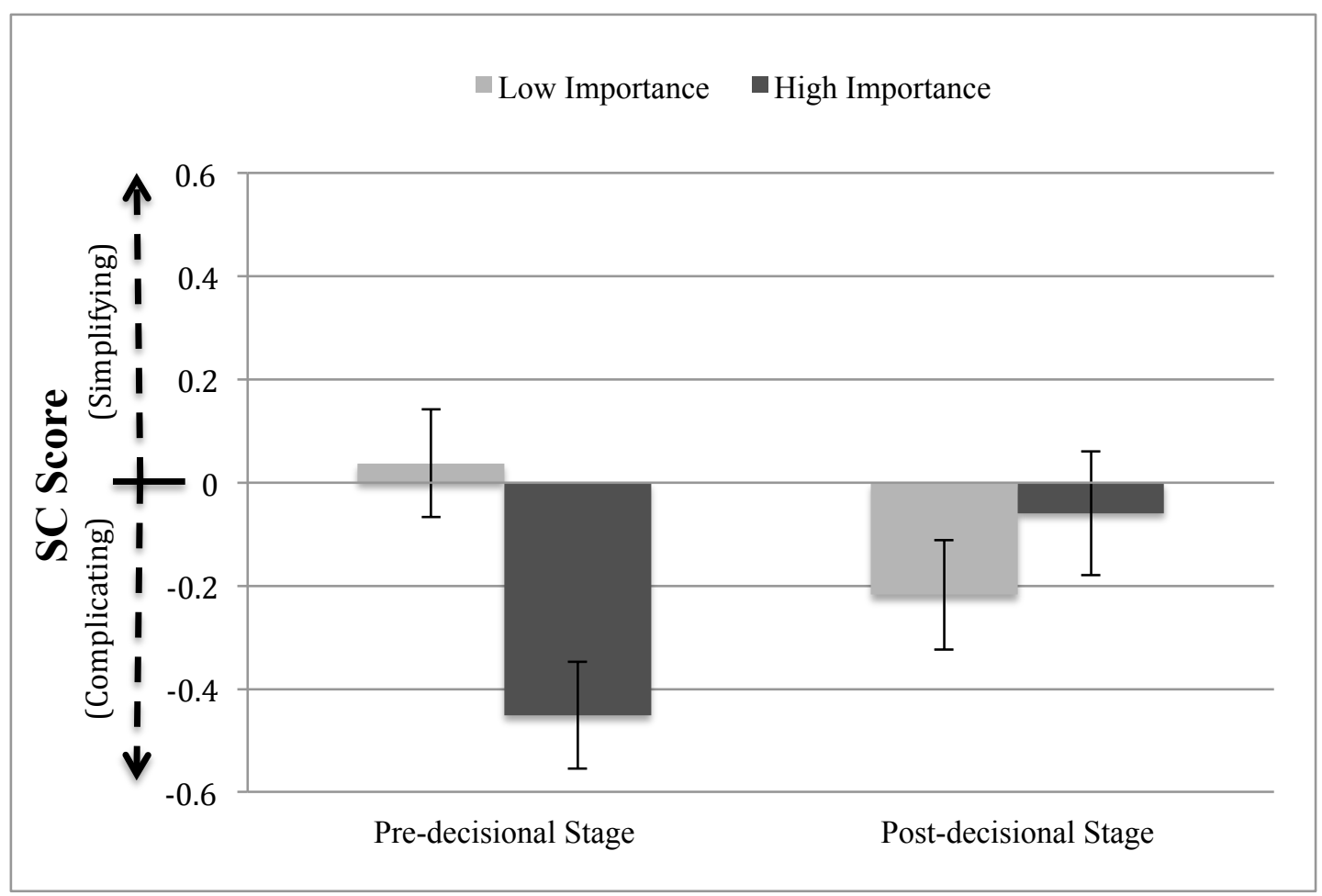




\section{Discussion}

This study provides additional evidence for conflict-increasing behavior in the deliberation phase of important yet seemingly easy decisions. Specifically, before choosing which of two job candidates to hire, participants recalled missing information in a manner that converged their evaluations of the candidates, thereby increasing participants' choice conflict. Further, as predicted by our conceptualization, such distortions were not observed after the hiring choice was made, and participants' recall was overall more accurate in the post-decisional stage. The finding that evaluations converge prior to, but not after, making a choice is inconsistent with market-efficiency inferences and conversational norms.

The results provide further evidence for our proposed psychological process, namely that people's tendency to link effort to positive outcomes drives behavior that complicates decision-making. Participants with a stronger belief in the Protestant Work Ethic exhibited increased complicating behavior (in the pre-, but not post-, decisional phase).

It is important to note that unlike Study 1, which explored the entire spectrum of choice difficulty (from easy to difficult choices), the current study focused only on relatively easy decisions that give rise to complicating behavior. Therefore, we neither predicted, nor observed, simplifying behavior. Additionally, in this study, distortions in recall were determined based on a benchmark of participants' recall outside the context of an impending decision (i.e., in the control condition). Thus, the study's results indicate that decision makers exhibited biased recall in a manner that complicated their choices.

Admittedly, while the study's results support the notion that people may bias their recall of information and complicate their decisions, it is also possible that participants complicated their decisions not through biased retrieval of information but rather via biased construction (or imputation) of missing information (see, e.g., Johnson \& Levin, 1985; 
Kivetz \& Simonson, 2000; Meyer, 1981). ${ }^{4}$ Specifically, the participants in Study 2a may have not remembered the original information presented in the first phase of the study, and instead, may have simply imputed (constructed) the missing information in a biased (and “complicating”) manner.

Although both biased retrieval of information and biased construction of missing information are consistent with our hypothesis, we conducted another study (Study 2b) to disentangle these two mechanisms. In Study $2 \mathrm{~b}$, participants were asked to review information about, and choose among, dating candidates (keeping the decision difficulty low as was done in Study 2a). The main difference between Study 2b's and Study 2a's experimental designs, which allowed us to discern whether conflict-increasing behavior was driven by biased recall or biased construction of missing information, was that the actual (true) values of the missing information were manipulated (between-subjects) so that they were either high or low for both alternatives. If participants indeed complicate by distorting what they actually recall about the alternatives, then they should use the true values as anchors from which they (insufficiently) adjust their memories. Therefore, the recalled values should be related to the actual values that participants initially saw (either high or low). However, if participants don't remember the original information and complicate by imputing missing information, then the true value of the missing information should not affect the values constructed (as opposed to recalled) by the participants.

\footnotetext{
${ }^{4}$ The distinction between biased retrieval versus construction of memories has been the subject of interesting scholarly research. For example, research on biased eyewitness memory examined how cues embedded in questions affect the recollection of events (e.g., Loftus, Altman \& Geballe, 1975; Loftus \& Zanni, 1975). In one study, after observing a film of a traffic accident, respondents were asked to estimate the speed of the cars when hitting each other, or alternatively, when smashing into each other. The latter phrasing produced recollections and estimates of higher speed. In such cases, it is unclear whether the cue embedded in the question triggered inferential processes that biased the response, or alternatively, that an actual change in the recollection of the event took place.
} 


\section{Study 2b: Biased Retrieval versus Construction of Missing Information}

\section{Method}

Participants and Procedure. Four hundred and five (405) undergraduate students from a large East Coast university participated in this two-part study (after completing an unrelated study). In the first part of the study, participants were asked to review information about eight potential candidates for a date (the information was ostensibly taken from an online dating website). Participants viewed each potential date's name (gender was conditioned on the participants' pre-measured dating preferences) as well as three scores ranging from 1 to 10: a compatibility score, an appearance score, and the user's profile score (scores ostensibly taken from other users of the website that rated the potential dates). After reviewing the information about all eight potential dates, participants completed an unrelated filler task and advanced to the second and final part of the study. In the second part, participants received a choice between two of the profiles they had previously seen. One of the two potential dates had a better compatibility score ( 9 vs. 8 ) and a higher appearance score ( 8 vs. 7 ). However, the information describing the profile scores was intentionally missing for both profiles. Thus, based solely on the available information, the choice seemed relatively easy as one potential date dominated the other.

Participants were then asked to complete the missing profile scores from memory either before choosing whom to date (i.e., pre-decisional condition) or immediately after choosing (i.e., post-decisional condition). As in Study 2a, in order to measure the baseline recall of information, we also included a control condition in which participants 
were asked to complete the missing information from memory outside the context of any choice between dating candidates.

The second factor that was manipulated between subjects was the exact value of the profile scores, which participants observed in the first, but not the second, part of the study. In the "high missing value" condition, the profile score was set to be 7 for both profiles that later appeared in the choice set. In the "low missing value" condition, the profile score was set to be 4 for both profiles that later appeared in the choice set. This manipulation enables us to test whether the observed distortions are due to imputing missing information or rather biased recall. If participants are increasing choice-conflict by constructing missing information and not by actually remembering distorted values, then we should not see a difference in the average values "recalled" in the high versus the low missing value conditions. However, if participants are indeed distorting what they recall about the alternatives, then they should use their memory as an anchor and (insufficiently) adjust from it; in such a case, significant differences should arise between the recalled values in the high versus the low missing value conditions.

\section{Results}

Dependent Variable. In order to examine whether, and to what extent, participants simplified versus complicated their decisions, we calculated the difference between the recalled information of the missing profile scores and formed a simplifying-complicating (SC) score. Specifically, we subtracted the information recalled about the "inferior" profile from that recalled about the "superior" profile. Because the original (true) scores for the two profiles on this dimension were identical (either 4 and 4 in the low missing value condition or 7 and 7 in the high missing value condition), a difference of zero indicates that 
the relative attractiveness of the two dating candidates was not distorted. However, a positive difference indicates that participants recalled the information in a manner that boosted the relative attractiveness of the "superior" profile, that is, a simplifying pattern. Conversely, a negative difference indicates a complicating pattern as the recalled information boosts the relative attractiveness of the "inferior" profile.

Analysis. In order to test our hypothesis, the SC-scores were submitted to a oneway ANOVA with the timing of recall (pre-decisional vs. post-decisional vs. control) as the independent variable. ${ }^{5}$ As hypothesized, the analysis revealed a significant difference between conditions $\left(\mathrm{F}(2,402)=4.29, p<.02, \eta_{\mathrm{p}}{ }^{2}=.02\right)$. Planned contrasts of the SCscores revealed that the average SC-score in the pre-decisional condition was negative and significantly lower than that observed in the control condition $\left(\mathrm{M}_{\mathrm{pre}}=-.38, \mathrm{SD}=\right.$ $\left.1.53, \mathrm{M}_{\text {control }}=.02, \mathrm{SD}=1.31, \mathrm{t}(263)=-2.3, \mathrm{~d}=-.28, p=.03\right)$ or in the post-decisional condition $\left(\mathrm{M}_{\text {post }}=.15, \mathrm{SD}=1.74, \mathrm{t}(263)=-2.64, \mathrm{~d}=-.33, p<.01\right)$. Thus, as hypothesized, the information that participants were asked to recall in the pre-decisional phase was recalled in a manner that intensified the choice conflict and complicated their dating choice (Figure 5). Additional analysis revealed that the proportion of participants who accurately recalled the exact missing values was significantly higher in the control condition than in the pre-decisional condition $\left(\mathrm{M}_{\text {control }}=25.7 \%, \mathrm{M}_{\text {pre-decisional }}=15.2 \%\right.$, $\left.\chi^{2}(1)=4.44, p<.05, \varphi=.13\right)$ or the post-decisional condition $\left(\mathrm{M}_{\text {post-decisional }}=14.3 \%\right.$, $\left.\chi^{2}(1)=5.71, p<.03, \varphi=.14\right)$. However, as can be seen from the absolute value of the mean SC-scores, the average accuracy was lowest in the pre-decisional condition.

\footnotetext{
${ }^{5}$ A full factorial ANOVA verified that the high vs. low value manipulation did not interact with the timing of recall conditions when examining the SC-scores. These conditions were therefore collapsed for the purpose of the main analysis.
} 
Figure 5. Memory Distortions (Simplifying-Complicating Scores) in the Pre- and Post-Decisional Stages

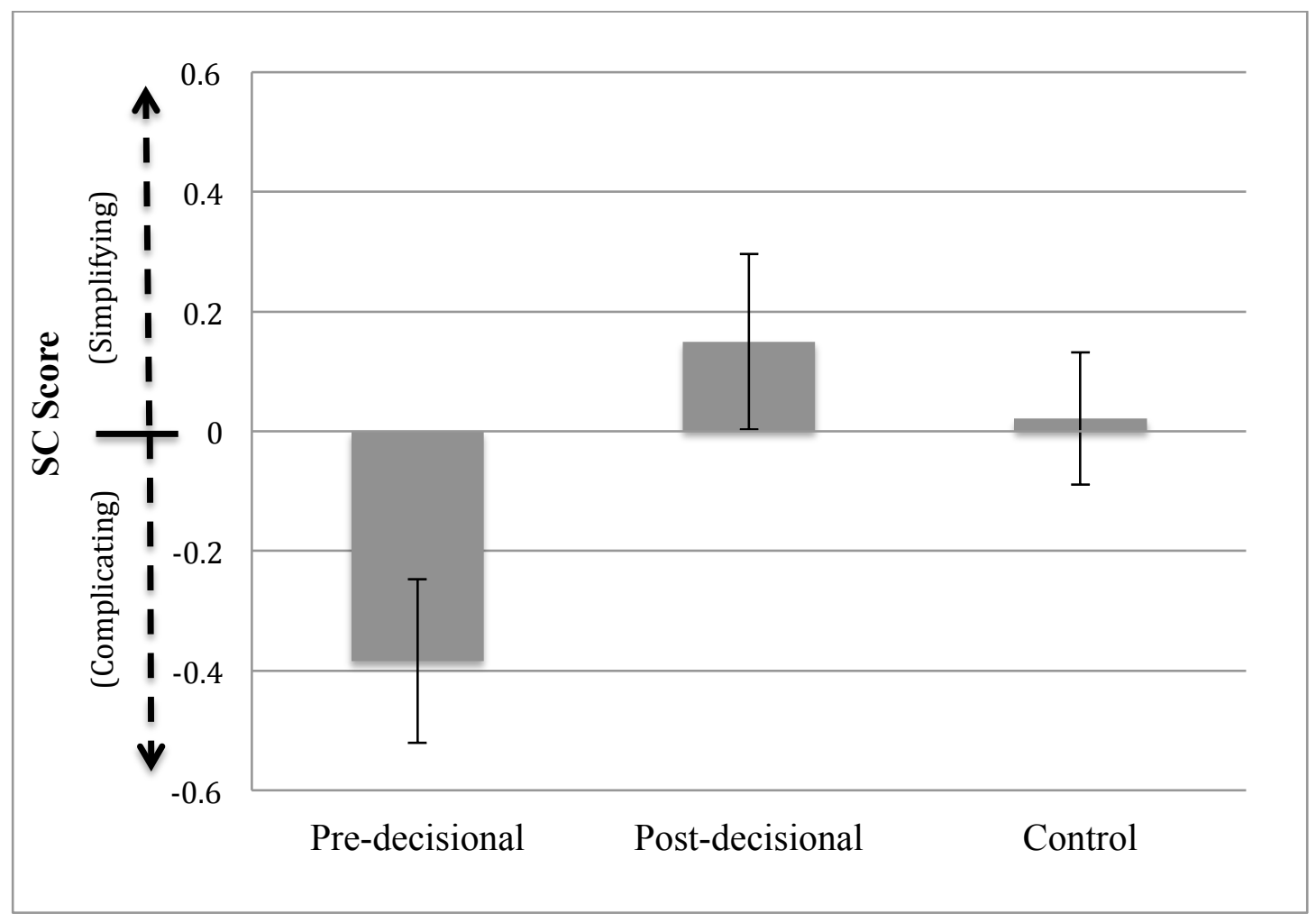

Average Recalled Values. Comparing the average recalled values between the high and low missing value conditions supports the notion that participants distort their memories rather than construct biased values on the fly. In particular, the average recalled value in the high missing value condition was significantly greater than that in the low missing value condition $\left(\mathrm{M}_{\text {high value }}=6.69, \mathrm{M}_{\text {low value }}=5.25, \mathrm{~F}(1,403)=238.88, p\right.$ $\left.<.001, \eta_{\mathrm{p}}{ }^{2}=.37\right)$. This difference was statistically significant and in the same direction when analyzing each of the experimental cells separately (pre-decisional, post-decisional, and control conditions; all $p$ 's $<.001$ ), and even when analyzing data only from participants who complicated (all $p$ 's $<.001$ ), suggesting that the result is not purely driven by heterogeneity across respondents (Hutchinson, Kamakura, and Lynch 2000). 
Thus, participants, including those who complicated their choices, actually recalled (albeit in a biased manner) information that they observed in the first part of the study.

\section{Discussion}

This study demonstrates complicating behavior through distortions of memory using a different decision context from those used in the prior studies. Participants who viewed information about potential dates (ostensibly taken from an online dating website) distorted the information they recalled about the potential dates in a manner that intensified choice conflict in the pre-decisional (but not post-decisional) stage. In addition, this study directly examined whether such complicating behavior occurs through biased retrieval, or rather biased construction, of missing information. The average recalled values significantly differed in the high versus low missing value conditions, supporting the notion that respondents "adjusted" their recall of information (as opposed to constructed values on the fly) in a manner that complicates their decisions.

\section{Study 3: Complicating Choice by Distorting the Interpretation of Information}

In Study 2a we found that stronger perceptions of a link between effort and positive outcomes leads decision-makers to distort the information they recall from memory in a manner that intensifies choice conflict. The purpose of Study 3 is to examine whether decision-makers will not only distort the information they recall from memory, but also interpret incoming information in a biased manner that intensifies choice conflict.

In order to do so, we presented participants with a binary-choice between cars, in which one car appeared superior to the other car. Before making their choice, we asked participants to interpret ambiguous information about the superior car. In addition, we employed a priming manipulation to influence beliefs about the EOL. We predicted that a 
stronger belief in the EOL would make participants interpret the ambiguous information as less supportive of the superior car, thus increasing their choice conflict and effectively complicating their decisions. Next, we describe the manipulation and a pretest that was employed to develop and validate the effectiveness of the priming manipulation. Then, we describe the main study.

Strong versus Weak EOL Belief Priming Manipulation. The purpose of the pretest was to validate the effectiveness of the EOL priming manipulation. ${ }^{6}$ Forty participants recruited from the national online subject pool Amazon Mechanical Turk were asked to read six quotes that advanced a certain idea and were then instructed to rank order these quotes from most effective to least effective. ${ }^{7}$ Participants were randomly assigned to one of two conditions. In the strong-EOL condition, participants observed and ranked six quotes that strongly supported the effort outcome link, whereas in the weak-EOL condition, participants observed and ranked six quotes that strongly opposed the effort outcome link. Table 2 displays the original quotes (as well as their modifications) that were used in the priming manipulation.

\footnotetext{
${ }^{6}$ Quinn \& Crocker (1999) manipulated beliefs in the Protestant Work Ethic using a similar priming manipulation.

${ }^{7}$ Data for four of the subjects was missing and therefore these respondents were dropped from the analysis.
} 
Supporting Effort-Outcome Link

Talent is cheaper than table salt. What separates the talented individual from the successful one is a lot of hard work. Stephen King

Life grants nothing to us mortals without hard work. Horace

There are no shortcuts to any place worth going. $\sim$ Beverly Sills

I know you've heard it a thousand times before. But it's true - hard work pays off. $\sim$ Ray Bradbury

Success for an athlete follows many years of hard work and dedication. Michael Diamond

A dream doesn't become reality through magic; it takes sweat, determination and hard work. $\sim$ Colin Powell

\section{Opposing Effort-Outcome Link}

Talent is cheaper than table salt. What separates the talented individual from the successful one is a lot of luck. (modified)

Enjoy your sweat because hard work doesn't guarantee success... A Alex Rodriguez

A good idea is about ten percent implementation and hard work, and luck is 90 percent. $\sim$ Guy Kawasaki

No, I don't believe in hard work. If something is hard, leave it. Let it come to you. Let it happen. Jeremy Irons

It is a pity that doing one's best does not always answer. $\sim$ Charlotte Bronte

A dream doesn't surely become reality through hard work; sometimes it takes magic, a strike of luck, to make it happen. (modified)

After rank-ordering the quotes, participants advanced to the next section of the pretest and were informed that the research team would like to know a little bit more about them. Participants then received four pairs of desirable values, traits, or concepts, 
and were asked to indicate (using a sliding scale ranging from 0 to 100) which of these values/traits/concepts they believed to be more important in life. We embedded the target pair (hard work vs. luck) within three other pairs (integrity vs. loyalty; fairness vs. self esteem; free will vs. compassion).

A multivariate analysis of variance confirmed that the priming manipulation was successful. The analysis confirmed a significant main effect only for the target dependent variable. As expected, participants generally believed that hard work is more important in life compared to luck, however, participants assigned to the strong EOL condition believed so more than did participants assigned to the weak EOL condition $\left(\mathrm{M}_{\text {strong }}\right.$ $\left.\mathrm{EOL}=78.7, \mathrm{M}_{\mathrm{weak} \mathrm{EOL}}=58.3, \mathrm{~F}(1,34)=5.31, p<.03, \eta_{\mathrm{p}}{ }^{2}=.14\right)$. No significant differences were found between the conditions for any of the other three pairs (all $p$ 's $>.17$ ).

\section{Main Study}

Participants and Procedure. One hundred twenty three (123) participants recruited from the national online subject pool Amazon Mechanical Turk participated in this two-part study (participants were told that they were recruited to participate in two unrelated studies). In the first part, participants were told that we would like to learn their opinion about the effectiveness of different quotes that try to advance a certain idea. Then, participants were randomly assigned to one of two priming conditions (strong- vs. weak-EOL) and were asked to rank order the six quotes corresponding to their condition (as outlined in the pretest). After rank ordering the quotes according to their effectiveness, participants were thanked and advanced to the second study.

In the second part of the study, participants were randomly assigned to one of two experimental conditions (choice vs. control). In the choice condition, participants were asked to imagine that they had decided to purchase a new car and were deliberating between two models. Participants received the Consumer Reports ratings of two models described in terms of performance, exterior, interior, safety, and overall ratings. Each of 
the car models was described on these dimensions using a rating that ranged from 4 to 10 (10 being "excellent" and 4 being "poor"). One of the car models had better ratings on all dimensions except safety, which was held constant for both alternatives. Thus, based on the available information, the decision between the two car models was quite easy.

Next, participants were told that a co-worker, which they do not know very well, had purchased Car A (the superior model) a few months ago and that he provided the following input about the car (this review was adapted from a real online review):

I'm satisfied with my purchase. The car is pretty spacious and has an upscale feel and a decent reputation for being a reliable car. It does have a limited trunk space compared to its rivals, and I did notice somewhat of harsh shifts from the automatic transmission. But, overall, it is comfortable, elegant and loaded with technology, although its newest navigation system is not that great.

The co-worker's input was constructed as relatively positive but with a few negative cues, thus leaving room for participants to interpret and distort their perceptions of how supportive was the co-worker's input. After reading the co-worker's input, participants were asked to indicate the extent to which they perceived the input as negative or positive (on a scale ranging from 1 - extremely negative to 10 - extremely positive).

This measure constitutes the study's dependent variable. ${ }^{8}$

In the control condition, we sought to estimate participants' interpretation of the co-worker's review outside the context of any impending choice, and therefore, without any motivation to distort the valence of such input. Therefore, the scenario in the control condition did not include an impending choice of a car that participants were about to

\footnotetext{
${ }^{8}$ After providing their perceptions using the above mentioned 10-point scale, participants were also asked what they believed would be their co-worker's overall rating of the car (using a scale ranging from 1-poor to 10 - excellent). This latter measure is projective, in that it requires participants to estimate the evaluations or preferences of another person. As discussed in the General Discussion of this manuscript, evaluations and decisions made about, or for, others may give rise to increased psychological distance and possibly attenuate the tendency to complicate decisions. Indeed, the results pertaining to the projective rating of the co-worker's evaluation of the car exhibited a similar, yet less pronounced, pattern compared to the participants' own perception of the input $(p=.012)$. Nevertheless, because our present conceptualization and hypothesis pertain to people's tendency to complicate decisions by distorting their own perceptions and preferences, we report below the results based only on the first measure and omit the second, projective measure.
} 
make. Participants received the same information about the superior car model coupled with its ratings from a recent Consumer Reports review. As in the experimental condition, participants were told that a co-worker who had recently purchased the car provided his input about the car. Then, participants in the control condition read the same review presented in the experimental condition and were asked to complete the same measure described in the experimental condition.

Finally, participants in all conditions were asked to state what they believed was the purpose of the study (no participant guessed the study's purpose and only two respondents raised the possibility that the first study had anything to do with the second study; analysis excluding these two participants produced similar results).

\section{Results}

Analysis. Respondents' estimations of the valence of the co-worker's input were submitted to a 2 (EOL prime: strong vs. weak) x 2 (experimental condition: choice vs. control) full factorial ANOVA. As expected, the analysis revealed a significant interaction between EOL prime and experimental condition $(\mathrm{F}(1,119)=7.76, p=.006$, $\left.\eta_{\mathrm{p}}{ }^{2}=.06\right)$. Consistent with our hypothesis, and as shown in Figure 6 below, participants assigned to the choice condition interpreted the input about the superior car as less positive when primed with strong EOL beliefs compared to those primed with weak EOL beliefs $\left(\mathrm{M}_{\text {strong_EOL }}=6.7, \mathrm{SD}=1.37, \mathrm{M}_{\text {weak_EOL }}=7.5, \mathrm{SD}=1.07, \mathrm{t}(60)=2.38, \mathrm{~d}=.62\right.$, $p=.02$ ). This finding supports the hypothesis that people distort incoming information in a manner that intensifies their choice conflict, particularly when they believe that effort relates to positive outcomes. No significant distortion of information was observed in the control conditions $\left(\mathrm{M}_{\text {strong_EOL }}=7.26, \mathrm{M}_{\text {weak_EOL }}=6.7, \mathrm{t}(59)=-1.6, p>.15\right)$ and, directionally, the pattern reversed. The results further underscore the motivational aspect of complicating behavior. Participants distorted incoming information in a manner that intensified choice conflict only when confronted with a choice. Taking out the need to 
choose and with it any sentiment for effort (in the control condition), attenuated participants' complicating behavior.

Figure 6. Perceived Positivity of Information as a Function of EOL Beliefs across Conditions

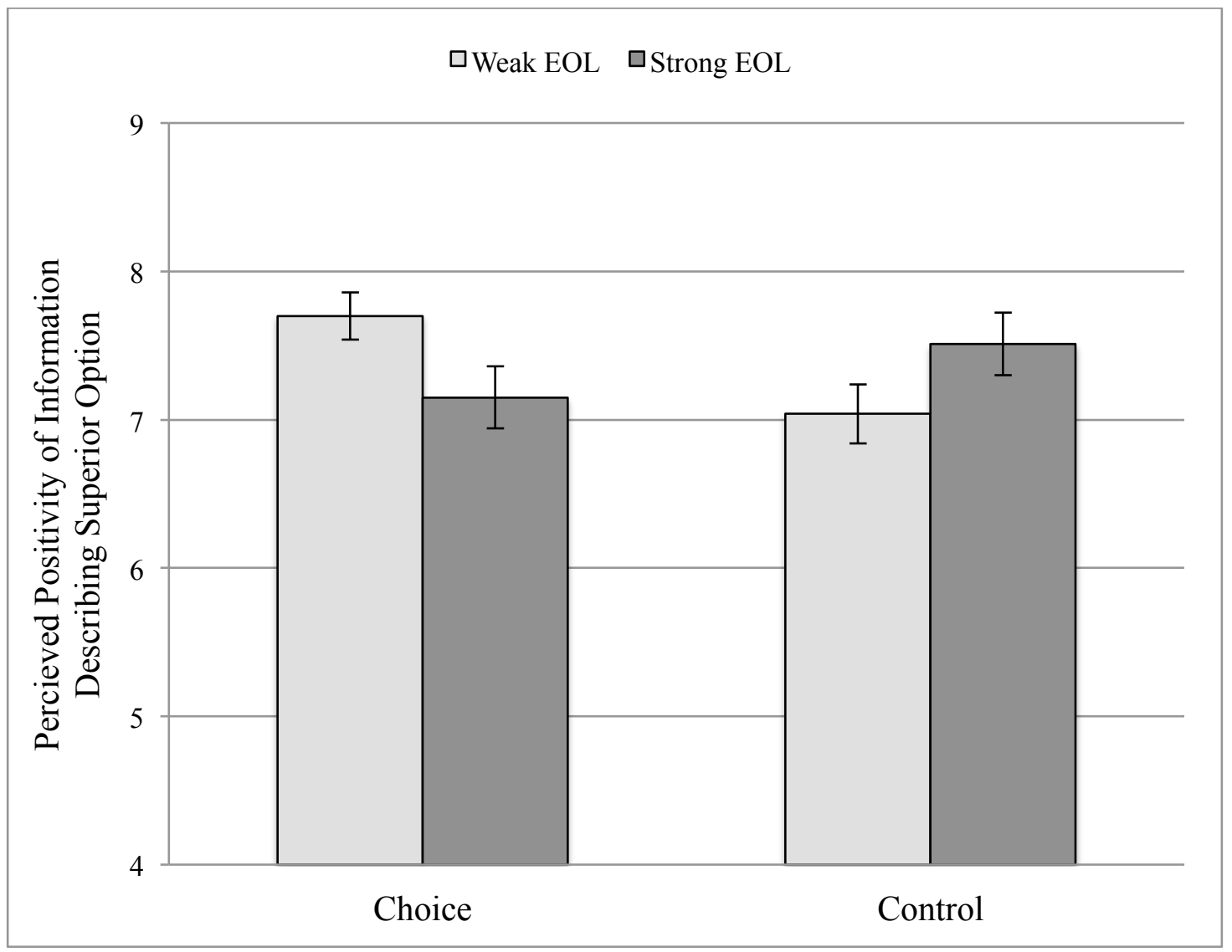

\section{Discussion}

Study 3 demonstrates that individuals with strong beliefs in the EOL complicate their decisions by distorting and interpreting incoming information in a manner that increases their choice conflict. Specifically, when reading relatively ambiguous information about a dominant alternative (a car) in a choice set, participants primed with strong beliefs about the EOL interpreted the information as less supportive of the superior alternative compared to participants primed with weak beliefs about the EOL. As 
expected, this pattern was not observed for participants in the control condition, who did not face an impending choice.

Taken together, the studies so far demonstrate that decision makers complicate easy decision by converging overall evaluations (Study 1), by distorting the information they recall from memory (Studies $2 \mathrm{a} \& 2 \mathrm{~b}$ ), and by interpreting ambiguous information (Study 3) in a manner that intensifies choice conflict. Further, the observed moderating effect of EOL beliefs is consistent with the proposed theoretical framework but not with the rival accounts. Additionally, complicating behavior was observed in the pre- (but not post-) decisional phase (Studies 2a \& 2b), was more pronounced when the decision was of high rather than low importance (Study 2a), and was eliminated when participants were not required to make a choice (Studies 1, 2a, 2b, and 3).

Although the aforementioned results all demonstrate a conflict-increasing behavior that complicates decisions, the reported studies so far did not measure the actual effort decision-makers invested in their decisions. If strong EOL beliefs lead individuals to engage in behaviors that complicate seemingly easy decisions, then such complicating should be accompanied by increased decision effort and information processing. For example, compared to people who do not complicate their decisions, people who do, are expected to spend more time and search for more information prior to finalizing their choice. Accordingly, in our final two studies, we broaden our investigation of complicating behavior and examine information search and decision time.

Next, we report Studies $4 \mathrm{a}$ and $4 \mathrm{~b}$, which investigates how much time people spend, and how much information they acquire, before making a decision.

\section{Study 4a: Complicating the Search for Information in Logo Choices}

In the current study we operationalize and test complicating behavior by measuring how much time participants spend on making their decision, as well as by 
examining the amount of information that individuals actively seek prior to finalizing their decision. Using such dependent variables requires a different experimental design from the designs employed in Studies 1 through 3. Specifically, in order to test for an increase in effort during choice (i.e., complicating) one needs to vet such behavior against the behavior observed in a context-independent (control) condition (in which no biases occur). In Studies 1 through 3 such a control was naturally available. For example, in Study 1, we compared respondents' evaluations of options, and identified divergence or convergence of these evaluations (i.e., simplifying or complicating, respectively) by using as a benchmark the evaluations of options outside the context of any choice. Similarly, in Studies 2 and 3 we compared recall and interpretation of information relative to a condition in which participants were not asked to make a choice. However, when examining effort-increasing behaviors using decision time and information search, such a natural control does not exist. That is, in contrast to evaluation and preference, decision time and information search cannot be meaningfully measured outside the context of any choice, and therefore, the designs cannot employ a non-choice control condition as a benchmark. More generally, any dependent variable that cannot be measured using a non-choice control condition (such as decision time and information search) will give rise to a similar challenge for discerning complicating behavior.

To address the aforementioned challenge, this study employs a different experimental design and analysis plan. In particular, participants who were randomly assigned to a difficult, moderately difficult, or an easy decision had the opportunity to acquire information about the available choice options before finalizing their choice. We measured how long participants spent on making the decision, as well as how much information they acquired. If no complicating behavior occurs, then decision time and information search should monotonously decrease as decisions become easier. In contrast, according to our complicating hypothesis, people will invest more time and acquire more information when making a decision not only when they encounter a 
difficult choice, but also when the choice feels too easy. That is, we expect that the relationship between the effort expended in the decision -- as measured via decision time and information search - and choice difficulty will exhibit a U-shape pattern. Study 4a tests both the complicating hypothesis described above and the moderating role of EOL beliefs by measuring participants' chronic tendency to link effort with positive outcomes using the PWE scale (Mirels \& Garrett, 1971).

\section{Method}

Participants and Procedure. One hundred and sixty eight (168) paid undergraduate students from a large East Coast university participated in this study. As in Study 1, in the first part of the study, participants reviewed 10 different fictitious company logos and were asked to rank and then rate each logo on a 0-15 liking scale. Then, after completing an unrelated filler task, participants were given the same scenario as in Study 1, which entailed choosing a logo for their own new company. Participants were randomly assigned to one of three choice difficulty conditions: high, moderate, or low. Specifically, based on their rankings in the first part of the study, participants received a choice between two logos that they ranked as $3^{\text {rd }}$ and $4^{\text {th }}, 3^{\text {rd }}$ and $6^{\text {th }}$, or $3^{\text {rd }}$ and $8^{\text {th }}$, in the high-, moderate-, and low-difficulty conditions, respectively.

Unlike Study 1, in the present study, participants were told that prior to making their choice they may view additional information that could assist them in making the choice. Participants were told that the logos were previously shown to a panel of individuals in an attempt to measure people's reactions to each of the logos. Participants were further told that each logo was presented separately to a different panel member who was asked to write the first 3 associations that came to mind when observing the logo. Participants were told that many such associations were collected for each logo, and that they can review as many associations as they would like before making their logo choice. Participants saw the two target logos (assigned specifically to them) on a 
computer screen, and underneath each logo three associations appeared representing a response of a certain panel member that reviewed that specific logo. Then, participants were prompted to either make their logo choice, or alternatively, continue to the next page and see an additional set of 3 associations for each of the two logos in their binary choice set. The actual associations that were used to describe each logo were drawn randomly from a pool of 106 adjectives that were all positive in valence (e.g., "reliable," prestigious," "novel," “trustworthy," "passionate," "spirited," "esteemed," "distinct”). After participants finished reviewing the associations and choose a logo, they were thanked and asked to participate in an unrelated lab study. Finally, at the end of the labsession, participants were asked to complete multiple items taken from the PWE scale similar to the scale used in Study 2a. An ANOVA confirmed that participants' PWE scores were not affected by the choice difficulty manipulation $(\mathrm{F}(2,165)<1$, n.s. $)$.

\section{Results}

Dependent Variables. The dependent variables in this study were: $(i)$ the total amount of time (measured in seconds) that participants spent on searching for information and making their logo choice; and (ii) the number of triplets of logo associations participants searched prior to making their choice.

Independent Variables. The independent variables in this study were: (i) decision difficulty, operationalized using the distance in rankings between the two logos in the participants binary choice set, with lower values indicating greater decision difficulty; and (ii) EOL beliefs, operationalized using participants' scores on the PWE scale.

Decision Time. An ANOVA revealed that the level of choice difficulty significantly impacted the time participants spent on acquiring information and making their logo choice $\left(\mathrm{F}(2,165)=3.06, p<.05, \eta_{\mathrm{p}}^{2}=.04\right)$. A trend-analysis supported the hypothesized U-shape pattern of decision time as a function of decision difficulty 
$\left(\mathrm{F}_{\text {linear }}(1,165)<1, p>.69 ; \mathrm{F}_{\text {quadratic }}(1,165)=5.96, p<.02\right)$. Planned contrasts revealed that participants that confronted either a very difficult or a very easy decision, took significantly longer to choose compared to those confronted with a moderately difficult decision $\left(\mathrm{M}_{\text {high-difficulty }}=38.3\right.$ seconds, $\mathrm{SD}=24.3$ vs. $\mathrm{M}_{\text {moderate-difficulty }}=30.23$ seconds, $\mathrm{SD}=13.77, \mathrm{t}(110)=2.15, \mathrm{~d}=.41, p<.04 ; \mathrm{M}_{\text {low-difficulty }}=39.93$ seconds, $\mathrm{SD}=26.4 \mathrm{vs}$. $\mathrm{M}_{\text {moderate-difficulty }}=30.23$ seconds, $\left.\mathrm{SD}=13.77, \mathrm{t}(110)=2.438, \mathrm{~d}=.46, p<.02\right)$. No significant difference in decision time was observed between the high and low-difficulty conditions $(p>.7)$.

In order to formally test the hypothesized U-shape pattern as well as to examine if EOL beliefs moderated the effect, we regressed the participant's decision time on: $(i)$ decision difficulty (using two dummy variables for high and low difficulty, with the moderate difficulty level serving as benchmark); (ii) the participant's score on the PWE scale (mean centered); and (iii) the two-way interaction between the PWE score and each of the dummy variables of decision difficulty. As hypothesized, the regression supported a U-shape pattern as a function of choice difficulty. Specifically, the regression coefficients for both the high and low decision difficulty were positive and significant $\left(\mathrm{B}_{\text {high-difficulty }}=\right.$ 8.32, $\left.\mathrm{SE}=4.08, p<.05 ; \mathrm{B}_{\text {low-difficulty }}=8.33, \mathrm{SE}=4.1, p<.05\right)$, indicating that relative to moderate level of choice difficulty, participants spent more time on making the high and low difficulty decisions. Additionally, and as hypothesized, the regression coefficient for the interaction between PWE and low decision difficulty was positive and significant ( $\mathrm{B}_{\mathrm{PWE}}$ $\mathrm{x}$ low-difficulty $=13.3, \mathrm{SE}=4.3, p<.002$ ), indicating that the tendency to spend more time on easy decisions was more pronounced for individuals with higher PWE. None of the other regression coefficients were significant. Figure 8a below depicts the average number of seconds participants took to make their choice in each decision difficulty condition broken down by weak versus strong EOL (using a median split). 
Figure 8a. Decision Time (in Seconds) as a Function of Decision Difficulty and EOL Beliefs

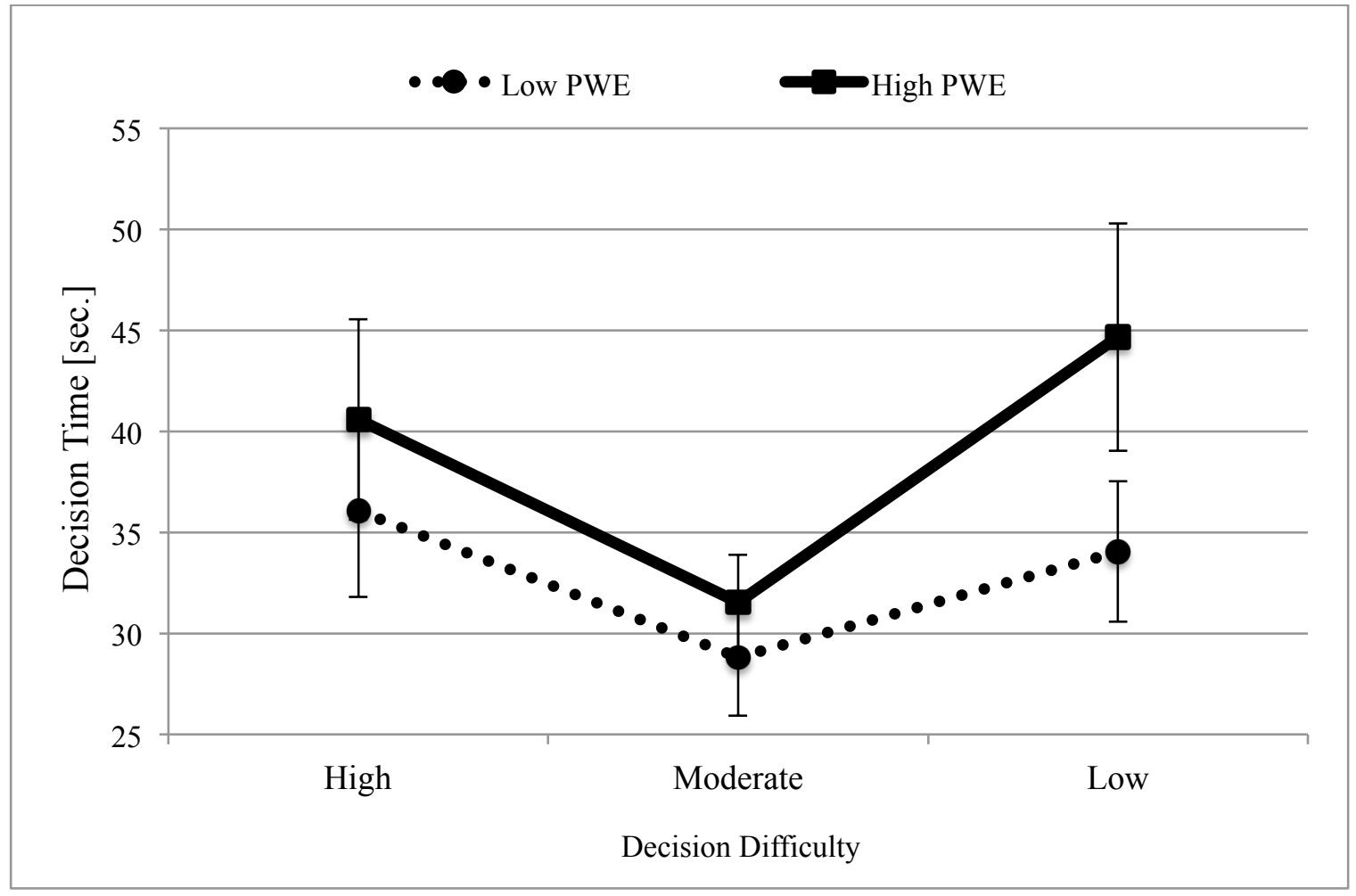

Amount of Search. An ANOVA revealed that the level of choice difficulty significantly impacted the amount of information participants acquired $(\mathrm{F}(2,165)=3.21, p$ $\left.<.05, \eta_{\mathrm{p}}{ }^{2}=.04\right)$. A trend-analysis supported the hypothesized U-shape pattern of the amount of information search as a function of decision difficulty $\left(\mathrm{F}_{\text {linear }}(1,165)<1, p>.87\right.$; $\left.\mathrm{F}_{\text {quadratic }}(1,165)=6.4, p<.012\right)$. Planned contrasts revealed that participants that confronted either a very difficult or a very easy decision, acquired significantly more information compared to those confronted with a moderately difficult decision $\left(\mathrm{M}_{\text {high- }}\right.$ difficulty $=2.12, \mathrm{SD}=3.2$ vs. $\mathrm{M}_{\text {moderate-difficulty }}=1.07, \mathrm{SD}=1.1, \mathrm{t}(110)=2.32, \mathrm{~d}=.44, p<$ $.025 ; \mathrm{M}_{\text {low-difficulty }}=2.01, \mathrm{SD}=2.56$ vs. $\mathrm{M}_{\text {moderate-difficulty }}=1.07, \mathrm{SD}=1.1, \mathrm{t}(110)=2.65, \mathrm{~d}=$ $.48, p<.01)$. No significant difference in information search was observed between the high and low-difficulty conditions $(p>.88)$. 
In order to formally test the hypothesized U-shape pattern as well as to examine if EOL beliefs moderated the effect, we regressed the number of association-sets that participants observed prior to making their choice on: $(i)$ decision difficulty (using two dummy variables for high and low difficulty, with the moderate difficulty level serving as benchmark); (ii) the participant's score on the PWE scale (mean centered); and (iii) the two-way interaction between the PWE score and each of the dummy variables of decision difficulty. As hypothesized, the amount of additional information that participants acquired prior to making their choice was a U-shape function of choice difficulty. In particular, the regression coefficients for both the high and low decision difficulty were positive and significant $\left(\mathrm{B}_{\text {high-difficulty }}=1.06, \mathrm{SE}=.46, p<.03 ; \mathrm{B}_{\text {low-difficulty }}=.87, \mathrm{SE}=.46, p<.06\right)$, indicating that relative to moderate level of choice difficulty, participants acquired more information when making the high and low difficulty decisions. Additionally, and as hypothesized, the regression coefficient for the interaction between PWE and low decision difficulty was positive and significant $\left(\mathrm{B}_{\mathrm{PWE} X \text { low-difficulty }}=1.12, \mathrm{SE}=.48, p<.03\right)$, indicating that the tendency to acquire more information when confronting an easy decisions was more pronounced for individuals with higher PWE. None of the other regression coefficients were significant. Figure $8 \mathrm{~b}$ below depicts the number of association-sets viewed in each decision difficulty condition broken down by weak versus strong EOL (using a median split). 
Figure 8b. Number of Association-sets Viewed as a Function of Decision Difficulty and EOL Beliefs

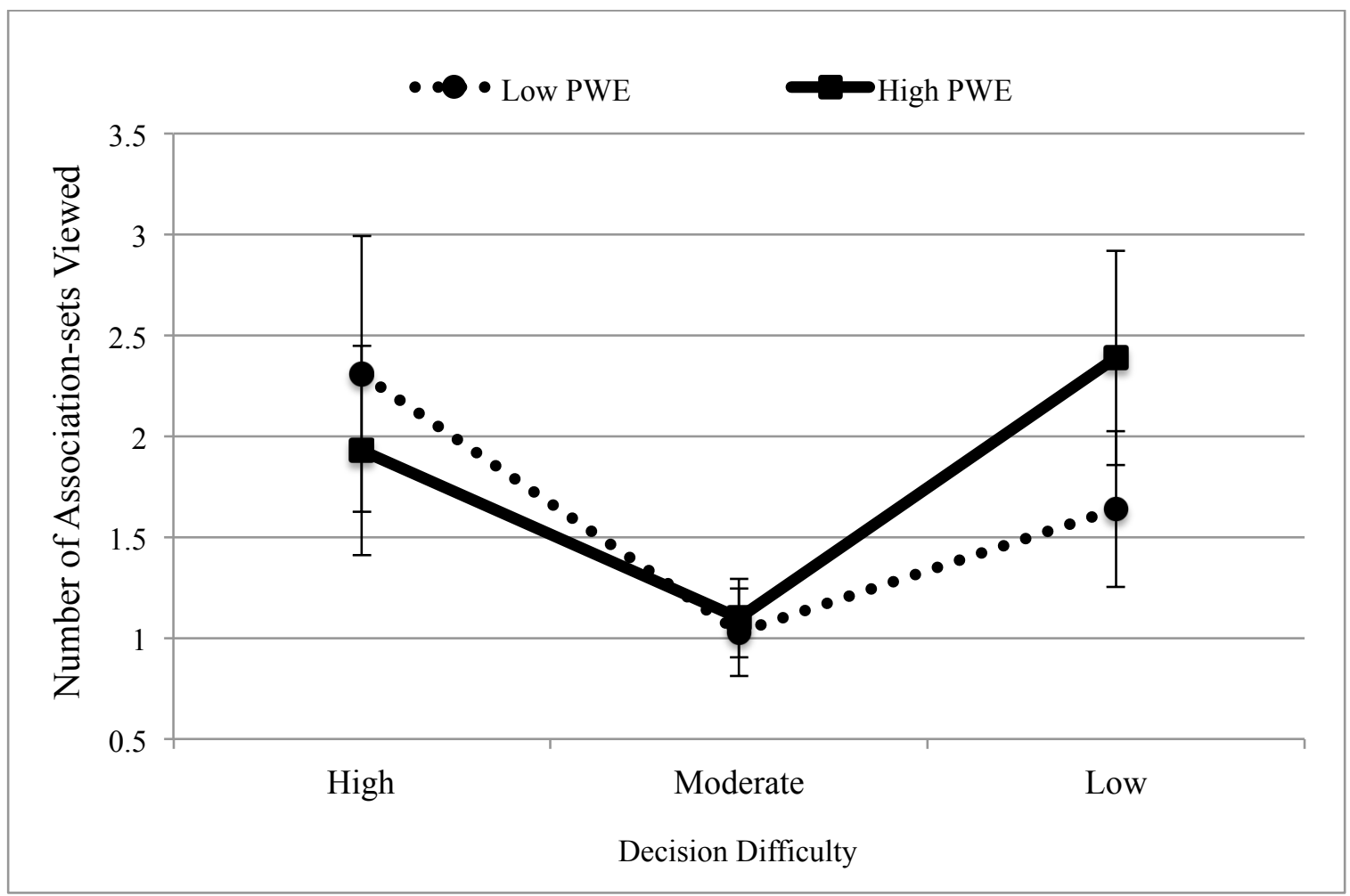

\section{Discussion}

Study 4a examined how much effort people exert at different levels of choice difficulty and as a function of their EOL beliefs. When choosing a company logo, decision-makers spent more time and searched for more information prior to finalizing their choice when the decision was very difficult or very easy (compared to when the decision was moderately difficult). That is, a U-shape pattern of decision time and information search as a function of choice difficulty was observed. Moreover, the tendency to conduct a superfluous information search when facing easy decisions was moderated by participants' EOL beliefs. Participants with a more pronounced belief in the link between effort and positive outcomes (i.e., participants with a stronger Protestant Work Ethic) exhibited increased complicating behavior (i.e., spent more time and acquired more 
information when facing easy decisions) compared to participants with a weaker belief in the EOL. Thus, this study compliments the findings of the previous studies by directly measuring the actual effort exerted (decision time and items searched) at different levels of choice difficulty.

\section{Study 4b: Complicating the Search for Information in Model Choices}

Study $4 \mathrm{~b}$ extends the findings observed in Study $4 \mathrm{a}$ in two ways. First, we employ a different decision domain, namely choosing a model for displaying jewelry. Second, we generalize complicating behavior to a different type of information search. Instead of measuring how much information participants acquire, we examine how many questions about the available options participants voluntarily generate prior to making their choice.

\section{Method}

Participants and Procedure. Eighty (80) paid subjects recruited from the national online subject pool Amazon Mechanical Turk participated in this study. ${ }^{9}$ In the first part of the study, participants reviewed pictures of 10 different female models (all pictures were of contestants in past beauty pageants) and were asked to rank each model based on their preferences keeping in mind that these models will be modeling different jewelry products. Then, after completing an unrelated filler task, participants were asked to imagine that they are managing a new line of jewelry products that will launch soon for a big chain of jewelry stores. As part of the launch they are looking to find the new model for this product line. Participants were also informed that the selected model would be featured in all of the jewelry line's advertisements and promotions, thus framing the decision as important for them and for the chain. Participants were then assigned to one of two choice difficulty conditions, either moderate difficulty or low

\footnotetext{
${ }^{9}$ Data for five participants was missing and these were therefore excluded from the analysis.
} 
difficulty. Based on their model rankings in the first part of the study, participants

received a binary choice between two models that they previously ranked as either $3^{\text {rd }}$ and $6^{\text {th }}$ or $3^{\text {rd }}$ and $9^{\text {th }}$ (i.e., moderate and low choice difficulty conditions, respectfully; manipulated between-subjects). Participants were told that they had to make a choice between the two models, who were currently available for the job.

Prior to making their jewelry model choice, participants were asked to imagine that they had the opportunity to gather more information about the models and were instructed to write down all their questions about the models prior to finalizing their choice. After writing all their questions, participants indicated their choice of a model and advanced to the next part of the study in which they were asked to complete the same Protestant Work Ethic (PWE) scale that was employed in Study 4a. An ANOVA verified that the PWE scores were not affected by the choice difficulty manipulation $(\mathrm{t}(73)<1$, n.s.). Finally, participants in all conditions were asked to state what they believed was the purpose of the study, and were also asked to indicate if they had seen before any of the models in this study. None of the participants successfully guessed the hypothesis or mentioned that they had previously seen the models.

\section{Results}

Dependent Variables. The dependent variable in this study consisted of the number of unique questions that each participant voluntarily generated prior to making a model choice. A research assistant, unaware of the research hypothesis or the participant's assigned condition, indicated how many distinct questions each participant generated.

Independent Variables. The independent variables in this study were: $(i)$ decision difficulty (moderate vs. low); and (ii) EOL beliefs (operationalized using participants' scores on the PWE scale). 
Number of Questions Generated. For ease of exposition, we first report the results using a median split of participants' scores on the PWE scale. An ANOVA revealed that the level of choice difficulty significantly impacted the number of questions that participants generated prior to choosing a model $\left(\mathrm{F}(1,71)=7.58, p<.01, \eta_{\mathrm{p}}{ }^{2}=.1\right)$. That is, participants in the low choice difficulty condition asked significantly more questions than participants in the moderate difficulty condition. In addition, the two-way interaction between decision difficulty and EOL beliefs was statistically significant $\left(\mathrm{F}(1,71)=5.47, p<.03, \eta_{\mathrm{p}}{ }^{2}=.07\right)$ and in the hypothesized direction. No main effect for the dichotomized EOL score was observed $(\mathrm{F}(1,71)<1$, n.s. $)$. Planned contrasts revealed that, in the low choice difficulty condition, participants with strong EOL beliefs generated significantly more questions $\left(\mathrm{M}_{\text {strong_EOL }}=4.94\right)$ than did participants with weak EOL beliefs $\left(\mathrm{M}_{\text {weak_EOL }}=3.78 ; \mathrm{t}(33)=2.21, p<.05\right)$. However, in the moderate difficulty condition, the amount of questions generated by participants did not significantly differ between those with strong versus weak EOL beliefs $\left(\mathrm{M}_{\text {strong_EOL }}=\right.$ $\left.3.14, \mathrm{M}_{\text {weak_EOL }}=3.63, \mathrm{t}(38)=1.03, p>.3\right)$. Figure 9 depicts the number of questions generated in each of the conditions. This pattern of results supports our conceptualization and hypothesis that decision makers with strong EOL beliefs expend more effort and seek additional information prior to finalizing their choice in a manner that effectively complicates easy decisions. 
Figure 9. Number of Questions Generated as a Function of Choice Difficulty and Effort Outcome Link (Protestant Work Ethic) Beliefs

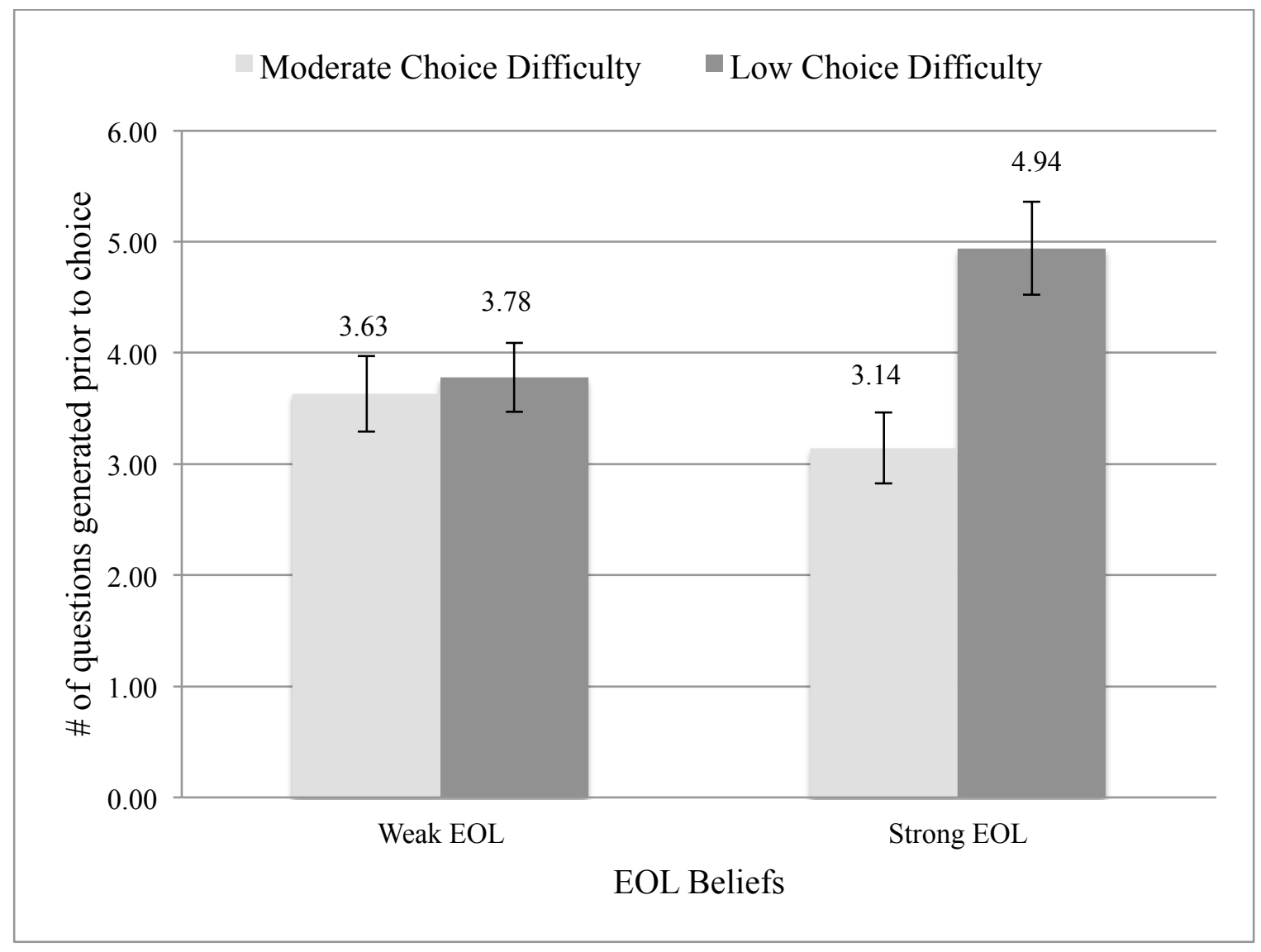

Continuous Analysis. To address the possible limitations of dichotomizing the data, we also employed a continuous analysis in which we regressed the number of questions generated on: $(i)$ choice difficulty (effect coded with $-1=$ moderate difficulty and $1=$ low difficulty); (ii) EOL measurement (mean centered); and (iii) the two-way interaction between choice difficulty and EOL score. As hypothesized, choice difficulty had a significant impact on the number of questions generated $\left(\mathrm{B}_{\text {choice difficulty }}=.484, \mathrm{SE}=\right.$ $.18, p<.01)$ indicating that participants generated more questions in the low difficulty condition. No significant main effect was observed for the EOL beliefs $\left(\mathrm{B}_{\mathrm{EOL}}=-.15, \mathrm{SE}=\right.$ $.28, p>.6)$. Additionally, as predicted, a significant interaction was observed ( $\mathrm{B}_{\text {choice difficulty }}$ 
$x \mathrm{EOL}=.59, \mathrm{SE}=.28, p=.05$ ) indicating that the greater number of questions generated for easier choices (i.e., the complicating behavior) was more pronounced among people who perceived the EOL as stronger.

\section{Discussion}

This study demonstrated that people who chose fashion models complicated their decisions and expended more effort by generating more questions about the choice options when they faced an easy decision. Such complicating behavior was moderated by participants' beliefs about the link between effort and positive outcomes, which was measured using the PWE scale. This study provides another demonstration for how the over-application of a work ethic heuristic can lead individuals to needlessly work harder on easy decisions.

\section{General Discussion}

Whether choosing which job candidate to hire, which person to date, or which property to buy, sometimes an apparently easy choice is indeed ripe for the making. In this article, we argue that a belief that positive outcomes are attained through diligent and effortful decisions may backfire and cause people to artificially construct a more effortful decision even when such choice conflict is unwarranted. Such superfluous deliberations may waste valuable resources, cause people to miss out on opportunities, and even lead to inferior choices.

The reported findings are important for several reasons. First, the results demonstrate how a commonly held belief may cause individuals to needlessly work harder on an impending decision. Second, this study explores an understudied 
phenomenon, namely pre-decisional convergence of evaluations ("complicating"), which is diametrically opposed to the extensively studied phenomenon of divergence of evaluations ("simplifying"). Third, the present research extends recent findings that demonstrate behaviors that essentially complicate decisions (e.g., Schrift et al., 2011) in that the current research offers and tests one potential reason for such behavior, namely the belief in the effort-outcome link. We validate this underlying psychological mechanism by manipulating (Studies $1 \& 3$ ) and measuring (Studies 2a, 4a, \& 4b) individuals' belief that effort yields positive outcomes. Finally, using a variety of decision contexts, the present research tests and demonstrates four distinct behaviors that essentially complicate choices: (i) distorting preferences (Study 1); (ii) distorting memories (Studies 2a \& 2b); (iii) distorting interpretations of new information (Study 3); and (iv) seeking additional information, which causes individuals to spend more time and exert greater effort on what should have been an easy decision (Studies $4 a \& 4 b$ ).

The Role of Habit Formation in Complicating Behavior: Automatic Goal Pursuit vs. Habitual Response. As we discussed earlier, complicating behaviors are unlikely to be conscious or deliberate. Decision-makers are unlikely to recognize that they are complicating their decisions and superfluously wasting resources (effort and time). Instead, individuals seem to follow a work-ethic heuristic that is over-generalized (overapplied) and that could lead to complicating decision patterns.

We suggest that two main forms of automaticity, namely automatic goal pursuit and habit-formation could potentially drive such patterns of behavior. To the extent that these two processes can be distinguished (see Aarts and Dijksterhuis, 2000), the present results appear to lend more support to the automatic goal pursuit explanation. In 
particular, according to a pure habitual account, people with strong EOL beliefs internalize over time a habit to work hard on decisions (no matter how easy these decisions initially appear). That is, effort is a learned response to a certain cue. The "cue" is a decision that needs to be made, and the "response" is the invested effort (e.g., Dickinson, 1985). While such a habit-formation account could still be consistent with the studies that measured beliefs in the EOL (Studies $2 \& 4$ ), this account is less consistent with the studies that manipulated such beliefs (Studies $1 \& 3$ ). The manipulations that were employed in these studies were "local" and singular, that is, specific to the study and without repetitions (i.e., a meta-cognitive manipulation in Study 1 and a priming manipulation in Study 3). Such single-shot manipulations of EOL should generally be less conducive for habit formation.

The literature on habit formation may also suggest that the reported complicating behavior is more consistent with automatic goal pursuit than with "pure" habit formation. Specifically, Wood and Neal (2007) proposed that when responses attract continued attention and when goals remain active during the development of automaticity, the formation of automatic goal pursuit is more likely than that of pure habits (i.e., direct context-response associations; see Wood and Neal 2007). We posit that, compared to many other behaviors and responses, decisions and choices are more likely to attract continued attention and activate goals. Thus, the formation and over-application of a work ethic heuristic and the resulting complicating behavior seems more consistent with automatic goal pursuit as opposed to pure habits.

The results of the post-test reported in Study 2a provide additional evidence that suggests respondents had an activated goal due to the specific task complexity as opposed 
to a global habitual response. In particular, in the post-test we measured how the decisionimportance manipulation influenced participants' motivation to perform well on the specific task of choosing a candidate. We found that, in the high-importance condition (compared to the low-importance condition), participants stated a greater motivation to choose the best candidate. The fact that complicating behavior was observed in the highimportance, but not in the low-importance condition, provides additional evidence that the complicating effect is triggered by an over-generalized work ethic heuristic that is consistent with automatic goal pursuit. Having said that, the goal of the current paper was not to disentangle between automatic versus non-automatic processes or validate one form of automaticity over the other. Future research should investigate the processes that lead people to complicate their decisions and the role of automaticity.

Conversational Norms and other Alternative Explanations. The six studies reported in this article rule out several rival accounts. Specifically, according to a conversational norms alternative explanation, participants' increased effort stems from a reflection about the researcher's motives. That is, participants are assumed to effectively ask themselves, "why would I be given such an easy decision and even be paid for it?," and answer, "I must be missing something here and perhaps this is not as trivial a decision as I thought it was." However, such a conversational norm account, which is essentially an inference-based account, cannot explain the results reported in this article. Specifically, the conversational norms (or inference) explanation suggests that respondents would question the easy decision they are faced with both before and after making the choice. In contrast, we found that complicating behavior only arose during the pre-decisional deliberation phase (i.e., before a choice was made). For example, 
Studies $2 \mathrm{a}$ and $2 \mathrm{~b}$ demonstrated that after a choice was made the observed memory distortions were attenuated. Importantly, these findings are consistent with our conceptual framework and an over-generalized work ethic heuristic, whereby complicating is a result of an unconscious "need" for effort (and accuracy) during the deliberation phase; further, once a choice is made, both effort and accuracy are no longer relevant, and thus, a work ethic heuristic would not be expected to have any impact.

The moderating role of decision importance casts further doubt on the conversational norms account. In particular, complicating behavior was observed when decision-makers perceived the decision as important but not when they perceived the same decision as unimportant. Participants' inferences about the researcher's motives should be the same regardless of the importance of the decision for the participants. In contrast, an over-generalized work ethic heuristic is expected to generate complicating behavior only when the decision is important.

Further, the moderating role of beliefs in the EOL is inconsistent with the conversational norms account. Specifically, a conversational norm account would need to predict that people with stronger EOL are more sensitive to such conversational norms. We do not see why this would be the case. If the motives of the researcher are called into question, then regardless of the EOL, individuals should engage in the same inferential process. While one may suggest that individuals who are higher or lower on the PWE scale may have correlated tendencies to be more sensitive to inference accounts (though we have no hypothesis in that direction), such correlated individual differences cannot explain the result obtained when we manipulate the EOL belief. An additional element in our experimental design that casts doubt on the conversational norms account involves 
the nature of the studies' stimuli. Specifically, throughout the studies, we used stimuli that involved subjective preferences, which are inherently associated with increased heterogeneity in tastes (e.g., preferences among fashion models and company logos are inherently subjective and variable). In such contexts, a choice between any two options may be considered difficult for some respondents but easy for others. Knowing this, respondents should be less likely to question the researcher's motives when confronted with what subjectively feels to them like a decision that is "too easy" (i.e., "too easy" for them). This, too, makes the conversational norms explanation less plausible.

In order to further address the conversational norms account we conducted an additional study that eliminates potential inferences about the researcher's motives. This study employed the same stimuli used in Study 1. Two hundred and four (204) participants were recruited from the national online subject pool Amazon Mechanical Turk (eight participants had incomplete responses and were eliminated from the analysis). Participants were first asked to rank and rate 10 logos. After a filler task, participants faced an easy choice between one logo that they originally ranked relatively high $\left(3^{\text {rd }}\right)$ and one that they ranked much lower $\left(7^{\text {th }}\right)$. As in Study 1, participants were either asked to re-rate the two logos prior to making their choice (i.e., in the predecisional condition), after making their choice (i.e., in the post-decisional condition), or simply re-rate the logos outside the context of any choice (i.e., in the control control). Unlike Study 1, before observing the choice set, participants were informed that the computer assigned different participants to a specific industry (e.g., fashion, hi-tech, consulting, automotive, perfumes, etc.) and that each participant will need to choose a logo for a company in that industry. Participants were also told that they will make the 
choices sequentially, that is, the first participant will chose one of the 10 available logos, the second respondent will choose a logo from the remaining nine logos, and so on.

After learning about the industry to which they were supposedly assigned (i.e., all respondents actually chose a logo for a consulting firm), the participants waited for about 20 seconds to ostensibly allow the computer to verify that the preceding choices of other group members were already collected and recorded. This procedure was intended to increase the study's realism. Then, participants were presented with two logos, which, supposedly, were the only two logos remaining (i.e., unchosen by other participants). Thus, to further rule out the conversational norms account, in this study, we explicitly provided participants with an external reason for the choice set construction. It is noteworthy that because we told participants about the multiple available industries, as well as the possible variance in peoples' preferences, inferences about the attractiveness of the remaining two logos were highly unlikely. Further, even if participants form inferences in the present study, such inferences are likely to be the same in all conditions (i.e., that the two remaining options are the least attractive), and therefore, could not explain our predicted pattern of results. Importantly, the external reason provided for the specific choice set facing the participant should eliminate any inferences about the researcher's motives.

Consistent with our predictions, we found that the SC-score in the pre-decisional condition was negative $\left(\mathrm{SC}_{\text {pre-decisional }}=-.98\right)$ and significantly different from the $\mathrm{SC}$ scores in the post-decisional condition $\left(\mathrm{SC}_{\text {post-decisional }}=1.33 ; \mathrm{t}(130)=3.43 ; \mathrm{d}=0.59\right.$; $p<.001)$ and in control condition (control $=.46 ; \mathrm{t}(117)=2.02 ; \mathrm{d}=0.37 ; p<.05)$. Thus, even after providing participants with an external reason for the choice-set construction, 
complicating patterns were observed in the pre-decisional phase (but not in the postdecisional phase or in the control [no choice] condition). These results demonstrate a complicating pattern in a situation on which the researcher's motives cannot be called into question and, therefore, conversational norms are unlikely to operate. ${ }^{10}$

The aforementioned analyses and findings also rule out other inferential accounts, such as market-efficiency inferences. Inferences that the alternatives in the choice set are located on the efficient frontier: (i) should also be made in the post-decisional stage; (ii) should not depend on the decision's importance for the participants; and (iii) should be less likely when the evaluation of options is inherently subjective and heterogeneous.

Future Research. Although the present research investigated several moderators of complicating behavior, future research should explore additional moderators and boundary conditions. Beyond the theoretical importance of such future research, it may also provide additional practical implications. That is, helping decision-makers avoid unnecessary complications. For example, in an unreported study, we found that complicating patterns attenuated when people were asked to help their friends make a choice (as opposed to when they made the same choice for themselves). This finding may provide initial support for the notion that psychological distance could help prevent overthinking and reduce the tendency to unnecessarily deliberate over easy (or non) decisions. Future research should also examine the relationship between complicating behaviors and "hyperopia," a form of psychological (excessive) farsightedness that leads

${ }^{10}$ We asked participants an attention question at the end of the study that confirmed that almost all participants (98\% or 191 out of 196) believed that their choice set was determined by the preceding choices that other participants made before them. Analyses with or without the five participants who failed the aforementioned attention check gave rise to similar results. 
people to deprive themselves of indulgence and instead overly focus on being industrious, acting responsibly, delaying gratification, and doing "the right thing" (e.g., Kivetz \& Simonson, 2002; Kivetz \& Keinan, 2006). Complicating behaviors and hyperopia may be related in multiple ways, including through the Protestant Work Ethic and other common antecedents and moderators (e.g., psychological distance appears to attenuate both hyperopia and complicating behaviors), and complicating behavior may, in fact, be a special case of hyperopia. Another factor that merits future research, and which may moderate complicating behavior, is the need to justify decisions, with a potentially interesting distinction between outcome and procedural accountability (e.g., Zhang \& Mittal, 2005).

Although this article focused on one driver of complicating behavior, namely the belief in the effort outcome link, we do acknowledge that in some cases other forces may give rise to complicating. For example, it is possible that, in certain instances, easier than expected decisions may threaten individuals' perceived freedom of choice and sense of agency (Brehm 1966). In such situations, a desire to reassert a sense of free choice or free will may result in behaviors that complicate decisions, effectively creating an "illusion of choice".

Need for coherence and cognitive consistency (e.g., Holyoak and Simon 1999; Russo et al. 2008; Simon et al. 2001) may offer another explanation for the reported patterns of effort-enhancing behaviors. The notion that individuals strive for consistency is congruent with the effort compatibility hypothesis (Schrift et al. 2011). That is, a mismatch between the anticipated and actual effort can trigger decision-makers to engage in behaviors that would either increase or decrease the effort they exert to match the 
anticipated effort. One might also argue that such need for coherence may operate in a bidirectional way and could explain the observed convergence of evaluations. According to this rival account, decision-makers infer that the decision was more difficult because of their invested effort. However, while such an account may be consistent with the observed converge of evaluations, it is less clear how such an account could explain the increase in actual effort, observed in Studies $4 \mathrm{a}$ and $4 \mathrm{~b}$, in which participants actually sought more information and spent more time on their task.

Future research can also examine the downstream (negative and positive) consequences of complicating behavior. On the one hand, complicating may cause individuals to expend superfluous resources and even forego valuable opportunities through choice deferral (e.g., Dhar, 1997; Dhar \& Nowlis, 2004; Parker \& Schrift, 2011). On the other hand, engaging in an effortful and diligent decision process (even when such is normatively not warranted) could potentially help decision-makers to decrease their anticipatory regret, enhance post-choice confidence and satisfaction, and possibly even mitigate the tendency to defer choices.

Although the present research documented that the belief that effort yields positive outcomes may lead to behaviors that complicate decisions, it is foolish to flout sage advice, such as that provided in the Babylonian Talmud and Ancient Greek literature (see earlier quotes by Rabbi Ben Hei and Sophocles). Indeed, life experience suggests that working hard is often associated with positive outcomes. However, sometimes we may be offered an alternative or course of action that is clearly superior, or we may simply have a strong and inherent preference for a specific person, product, place or any other object or course of action (Simonson 2008; see also, Kivetz, Netzer, and Schrift 
2008). In such cases, an "illusion of choice" may take hold, whereby to feel like "responsible" decision makers, we end up complicating what should otherwise have been an obvious, or non-, choice. 


\section{References}

Aarts, H., \& Dijksterhuis, A. (2000). Habits as Knowledge Structures: Automaticity in Goal-directed Behavior. Journal of Personality and Social Psychology, 78(1), 53.

Bargh, J. A. (1989). Conditional Automaticity: Varieties of Automatic Influence in Social Perception and Cognition. In Uleman, J. S., \& Bargh, J. A. (Eds.). Unintended Thought (pp. 51-69). Guilford Press.

Bargh, J. A., Gollwitzer, P. M., Lee-Chai, A., Barndollar, K., \& Trötschel, R. (2001).

Bypassing the Will: Automatic and Controlled Self-regulation. Journal of Personality and Social Psychology, 81, 1014-1027.

Bem, D. J. (1967). Self-Perception: An Alternative Interpretation of Cognitive Dissonance Phenomena. Psychologica Review, 74(3), 183-200.

Braine, M. D. S., Reiser, B. J., \& Rumain, B. (1984). Some Empirical Justification for a Theory of Natural Proposition Logic. In G. H. Bower (Ed.), The Psychology of Learning and Motivation (313-371). New York: Academic Press.

Brehm, J. W. (1956). Postdecision Changes in the Desirability of Alternatives. The Journal of Abnormal and Social Psychology, 52(3), 384-389.

Brownstein, A. L. (2003). Biased Predecision Processing. Psychological Bulletin, 129(4), $545-568$.

Chaiken, S. (1980). Heuristic Versus Systematic Information Processing and the Use of Source Versus Message Cues in Persuasion. Journal of Personality and Social Psychology, 39(5), 752-766.

Dhar, R. (1997). Consumer Preference for a No-Choice Option. Journal of Consumer Research, 24(2), 215-231. 
Dhar, R., \& Nowlis, M. S. (2004). To Buy or Not to Buy: Response Mode Effects on Consumer Choice. Journal of Marketing Research, 41(4), 423-432.

Dickinson, A. (1985). Actions and Habits: The Development of Behavioural Autonomy. Philosophical Transactions of the Royal Society B: Biological Sciences, 308(1135), 67-78.

Evans, J. St. B. D. (1982). The Psychology of Deductive Reasoning. London: Routledge \& Kegan Paul.

Festinger, L. (1957). A Theory of Cognitive Dissonance. Stanford University Press.

Janis, I. L., \& Mann L. (1977). Decision making: A psychological Analysis of Conflict, Choice, and Commitment. New York: Free Press.

Johnson, R. D., \& Levin, I. P. (1985). More Than Meets the Eye: The Effect of Missing Information on Purchase Evaluations. Journal of Consumer Research, 12(2), 169177.

Holyoak, K. J., \& Simon, D. (1999). Bidirectional reasoning in decision making by constraint satisfaction. Journal of Experimental Psychology: General, 128(1), 331.

Hutchinson, J. Wesley, Wagner A. Kamakura, \& John G. Lynch Jr. (2000) Unobserved Heterogeneity as an Alternative Explanation for "Reversal" Effects in Behavioral Research. Journal of Consumer Research, 27(3), 324-344.

Kim, S., \& Labroo, A. A. (2011). From Inherent Value to Incentive Value: When and Why Pointless Effort Enhances Consumer Preference. Journal of Consumer Research, 38(4), 712-742. 
Kivetz, R., \& Simonson, I. (2000). The Effects of Incomplete Information on Consumer Choice. Journal of Marketing Research, 37(4), 427-448.

Kivetz, R., \& Simonson, I. (2002). Earning the right to indulge: Effort as a determinant of customer preferences toward frequency program rewards. Journal of Marketing Research, 39(2), 155-170.

Kivetz, R., \& Keinan, A. (2006). Repenting hyperopia: An analysis of self-control regrets. Journal of Consumer Research, 33(2), 273-282.

Kivetz, R., \& Zheng, Y. (2006). Determinants of Justification and Self-Control. Journal of Experimental Psychology: General, 135(4), 572-587.

Kruger, J., Wirtz, D., Van Boven, L., \& Altermatt, T. W. (2004). The Effort Heuristic. Journal of Experimental Social Psychology, 40(1), 91-98.

Kruglanski, A. W. (1990). Lay Epistemic Theory in Social-cognitive Psychology. Psychological Inquiry, 1(3), 181-197.

Kruglanski, A. W., \& Webster D. M. (1996). Motivated Closing of the Mind: Seizing and Freezing. Psychological Review, 103(2), 263-283.

Kunda, Z. (1990). The Case for Motivated Reasoning. Psychological Bulletin, 108(3), 480-498.

Labroo, A. A., \& Kim, S. (2009). The instrumentality Heuristic: Why Metacognitive Difficulty is Desirable During Goal Pursuit. Psychological Science, 20(1), 127134.

Lerner, M. J., (1980). The Belief in a Just World: A Fundamental Delusion. New York: Plenum Press. 
Loftus, E. F., Altman, D., \& Geballe, R. (1975). Effects of Questioning Upon a Witness' Later Recollections. Journal of Police Science \& Administration, 3(2), 162-165.

Loftus, E. F., \& Zanni, G. (1975). Eyewitness Testimony: The Influence of the Wording of a Question. Bulletin of the Psychonomic Society.

Lord, C. G., Ross, L., \& Lepper, M. R. (1979). Biased Assimilation and Attitude Polarization: The Effects of Prior Theories on Subsequently Considered Evidence. Journal of Personality and Social Psychology, 37(11), 2098-2109.

Mann, L., Janis, I. L., \& Chaplin, R. (1969). Effects of Anticipation of Forthcoming Information on Predecisional Processes. Journal of Personality and Social Psychology, 11(1), 10-16.

Mann, L., \& Taylor, V. A. (1970). The Effects of Commitment and Choice Difficulty on Predecision Processes. Journal of Social Psychology, 82 (2), 221-230.

Mayseless, O., \& Kruglanski, A. W. (1987). What Makes You So Sure? Effects of Epistemic Motivations on Judgmental Confidence. Organizational Behavior and Human Decision Processes, 39, 162-183.

Meyer, R. J. (1981). A Model of Multiattribute Judgment Under Attribute Uncertainty and Informational Constraints. Journal of Marketing Research, 18(4), 428-441.

Mills, J. (1968). Interest in Supporting and Discrepant Information. In R. P. Abelson et al. (Eds.), Theories of Cognitive Consistency: A Source Book (771-776). Chicago: Rand McNally.

Mirels, H. L., \& Garrett, J. B. (1971). The Protestant Ethic as a Personality Variable. Journal of Consulting and Clinical Psychology, 36(1), 40-44. 
Montgomery, H. (1983). Decision Rules and the Search for a Dominance Structure:

Towards a Process Model of Decision Making. In P. Humphreys, O. Svenson, \& A. Vari (Eds.), Analyzing and Aiding Decision Processes (pp. 343-369). Amsterdam: North Holland.

Morales, A. C. (2005). Giving Firms an "E” for Effort: Consumer Responses to HighEffort Firms. Journal of Consumer Research, 31(4), 806-812.

Parker, J. R., \& Schrift, R. Y. (2011). Rejectable Choice Sets: How seemingly Irrelevant No-choice Options Affect Consumer Decision Processes. Journal of Marketing Research, 48(5), 840-854.

Payne, J. W., Bettman, J. R., \& Johnson, E. J. (1988). Adaptive Strategy Selection in Decision Making. Journal of Experimental Psychology: Learning, Memory, and Cognition, 14(3), 534-552.

Pyszczynski, T., \& Greenberg, J. (1987). Toward an Integration of Cognitive and Motivational Perspectives on Social Inference: A Biased Hypothesis-testing Model. In L. Berkowitz (Eds.), Advances in Experimental Social Psychology (297-340). San Diego: Academic Press.

Quattrone, G. A., \& Tversky, A. (1984). Causal Versus Diagnostic Contingencies: On Self-Deception and on the Voter's Illusion. Journal of Personality and Social Psychology, 46(2), 237-248.

Quinn, D. M., \& Crocker, J. (1999). When Ideology Hurts: Effects of Belief in the Protestant Ethic and Feeling Overweight on the Psychological Well-being of Women. Journal of personality and social psychology, 77(2), 402-414. 
Russo, E. J., Medvec, V. H., \& Meloy, M. G. (1996). The Distortion of Information During Decisions. Organizational Behavior and Human Decision Processes, $66(1), 102-110$.

Russo, E. J., Meloy, M. G., \& Wilks, J. T. (2000). Predecisional Distortion of Information by Auditors and Salespersons. Management Science, 46(1), 13-27.

Russo, J. E., Carlson, K. A., Meloy, M. G., \& Yong, K. (2008). The goal of consistency as a cause of information distortion. Journal of Experimental Psychology: General, 137(3), 456-470.

Schrift, R. Y., Netzer, O., \& Kivetz, R. (2011). Complicating Choice. Journal of Marketing Research, 48(2), 308-326.

Schwarz, N., Bless, H., Strack, F., Klumpp, G., Rittenauer-Schatka, H., \& Simons, A. (1991). Ease of Retrieval as Information: Another Look at the Availability Heuristic. Journal of Personality and Social Psychology, 61(2), 195-202.

Schwarz, N. (1999). Self-Reports: How the Questions Shape the Answers. American Psychologist, 54(2), 93.

Sela, A., \& Berger, J. A. (2012). Decision Quicksand: When Trivial Choices Suck Us in. Journal of Consumer Research, 39(2), 360-370.

Simon, D., Pham, L. B., Le, Q. A., \& Holyoak, K. J. (2001). The emergence of coherence over the course of decision making. Journal of Experimental Psychology: Learning, Memory, and Cognition, 27(5), 1250-1260.

Svenson, O. (1992). Differentiation and Consolidation Theory of Human Decision Making: A Frame of Reference for the Study of Pre- and Postdecision Processes. Acta Psychologica, 80(1), 143-168. 
Taplin, J. E., \& Staudenmayer, H. (1973). Interpretation of Abstract Conditional Sentences in Deductive Reasoning. Journal of Verbal Learning and Verbal Behavior, 12, 530-542.

Thompson, V. A. (1994). Interpretational Factors in Conditional Reasoning. Memory and Cognition, 22(6), 742-758.

Weber, M. (1958). The Protestant ethic and the spirit of capitalism. New York: Scribner's Press.

Wood, W., \& Neal, D. T. (2007). A New Look at Habits and the Habit-goal Interface. Psychological Review, 114(4), 843.

Zhang, Y., \& Mittal V. (2005). Decision Difficulty: Effects of Procedural and Outcome Accountability. Journal of Consumer Research, 32(3), 465-472. 
APPENDIX A: Simplifying-Complicating (SC) Scores in Study 1 Broken by EOL

Manipulation Type

Statements Supporting the EOL

\begin{tabular}{|l|ccc|}
\cline { 2 - 4 } \multicolumn{1}{c|}{} & \multicolumn{3}{c|}{ Decision Difficulty } \\
\cline { 2 - 4 } \multicolumn{1}{c|}{} & Low & Moderate & High \\
\hline $\begin{array}{c}\text { Strong EOL } \\
\text { 1-example }\end{array}$ & $\begin{array}{c}-2.93 \\
\text { (complicating) }\end{array}$ & 0.66 & $\begin{array}{c}2.73 \\
\text { (simplifying) }\end{array}$ \\
\hline $\begin{array}{c}\text { Weak EOL } \\
\text { 5-examples }\end{array}$ & 0.62 & -0.12 & $\begin{array}{c}2.43 \\
\text { (simplifying) }\end{array}$ \\
\hline
\end{tabular}

Statements Opposing the EOL

\begin{tabular}{|l|ccc|}
\cline { 2 - 4 } \multicolumn{1}{c|}{} & \multicolumn{3}{c|}{ Decision Difficulty } \\
\cline { 2 - 4 } \multicolumn{1}{c|}{} & Low & Moderate & High \\
\hline $\begin{array}{c}\text { Strong EOL } \\
\text { 5-examples }\end{array}$ & $\begin{array}{l}-2.3 \\
\text { (complicating) }\end{array}$ & 0.68 & $\begin{array}{c}2.06 \\
\text { (simplifying) }\end{array}$ \\
\hline $\begin{array}{l}\text { Weak EOL } \\
\text { 1-example }\end{array}$ & 1.05 & 0.41 & $\begin{array}{c}1.93 \\
\text { (simplifying) }\end{array}$ \\
\hline
\end{tabular}

